\title{
The Impact of Educational Content on Anti-Immigrant Attitudes*
}

\author{
Boyoon Lee Le $^{\dagger}$ \\ Pennsylvania State University
}

\begin{abstract}
How does education affect attitudes towards immigrants? Shifting the scholarly focus from levels of education to educational content, I argue that the effect of education depends on the type of national identification that educational content promotes. Content that promotes a narrower form of national belonging fosters more negative attitudes towards immigrants because it emphasizes a more exclusive notion of national membership. To test the implications of my theory, I leverage a textbook reform in Taiwan that introduced a new narrative promoting Taiwanese identity based on a common ancestral and historical background. Using a difference-in-differences design that compares academic and vocational paths affected differently by the reform, I find that the consumption of educational content emphasizing a narrower form of national identification induces exclusionary attitudes towards immigrants. The evidence suggests that higher levels of education do not necessarily increase positive attitudes towards outsiders - it depends on what is taught.
\end{abstract}

Keywords: anti-immigrant attitudes, education, nationalism, difference-in-differences, Taiwan

${ }^{*}$ I thank Ted Chen, Charles Crabtree, Bruce Desmarais, Matt Golder, Sona Golder, John Holbein, Amy Liu, Fan Lu, Javier Rodríguez, Joseph Wright, Xu Xu, Omer Yalcin, Boliang Zhu, CP group members at Penn State, American Political Science Association Annual Meeting \& Exhibition 2020 conference attendees, AOPSSS meeting attendees, Visions In Methodology 2021 conference attendees, and visiting researchers at the Institute of Social Science at the University of Tokyo for helpful comments. All data and computer code necessary to replicate the results in this analysis will be made publicly available on my webpage at https://boyoonlee.com/

${ }^{\dagger}$ Ph.D. Candidate, Department of Political Science, Pennsylvania State University, 214 Pond Lab, University Park, PA 16802 (bul70@psu.edu). 
How does education affect attitudes towards immigrants? The existing literature consistently finds that higher levels of education are strongly associated with more favorable views towards immigration and immigrants (see Hainmueller and Hopkins, 2014 for a comprehensive review). The positive effect is often attributed to two pathways by which education might affect immigration attitudes. One pathway has to do with an education premium in wages, employment opportunities, and other general life experiences (Mayda, 2006; Citrin et al., 1997). The successful completion of higher education raises individual's skills and qualifications, which then make highly educated individuals less likely to feel threatened by immigrants and thus less likely to hold anti-immigration attitudes (Hainmueller and Hiscox, 2007, 2010). The second pathway focuses on the "character-shaping" role of education (Cavaillé and Marshall, 2019). According to this second pathway, individual attitudes are directly influenced by the explicit promotion of tolerance and open-mindedness during their educational experience (Hainmueller and Hopkins, 2014). A critical assumption in the second causal story is that the content of education promotes liberal and tolerant values. However, this assumption is often left implicit and untested in existing studies.

The assumption that education promotes tolerance and open-mindedness may be reasonable in the North American and European contexts, where official learning objectives often highlight the desire to promote liberal values. For example, the purpose of social studies classes in grades pre-K through 12 in the United States is "to help young people make informed and reasoned decisions for the public good as citizens of a culturally diverse, democratic society in an interdependent world" (NCSS, 2010). The general tendency to promote liberal content in North America and Europe, however, does not imply that all countries emphasize liberal content in their education systems. The finding that higher levels of education increases tolerant attitudes towards immigrants may simply be the result of averaging effects over more countries with liberal educational content than countries with illiberal content. This is important because there is growing evidence that the degree to which educational content emphasizes tolerance and cosmopolitanism varies across different national and educational contexts around the world (Lerch, Russell and Ramirez, 2017).

My study contributes to the existing literature by examining whether and how educational 
content affects attitudes towards immigrants. Connecting the literature on education and nationalism with social identity theory, I argue that educational content takes different approaches to defining membership in a national community and that this shapes the attitudes that people have to outsiders. When educational content emphasizes a narrower and more exclusive form of national identification that reifies inflexible attributes such as place of birth, national ancestry, ethnicity, and race, the enhanced distinctiveness and restrictiveness of membership in the national community may trigger nationalist sentiment and fuel hostility towards immigrants who do not share the same characteristics.

To evaluate the causal effect of educational content on attitudes towards immigrants, I leverage a textbook reform that took place in Taiwan in 1997. In pursuit of promoting a narrower and more distinct Taiwanese national identity, the Taiwanese government published a new junior high school textbook series, known as Renshi Taiwan (Knowing Taiwan). The goal of the new textbooks was to establish Taiwanese uniqueness and more clearly distinguish Taiwanese identity from a broader Chinese identity (Corcuff, 2013). Among other things, they sought to do this by more narrowly defining the national territory to the islands of Taiwan and by linking the newly defined national boundary to common historical roots and ancestral ties.

I use a difference-in-differences design that leverages variation in both educational content and the intensity with which this educational content is consumed. To be specific, I compare two educational paths that were affected differently by the introduction of the textbook reform: the vocational path and the academic path. In Taiwan, junior high school students select into one of these two educational paths. A key component of my research design is that each educational path creates different incentives for students when it comes to studying school textbooks. In particular, one can expect that students pursuing the academic path will study the educational content more extensively because they need to pass the High School Entrance Exam before proceeding to senior high school. In contrast, students taking the vocational path have fewer incentives to consume educational content because they do not need to take the exam. This variation in the intensity of educational content consumption allows me to compare students who absorbed the content (academic path) and those who did 
not (vocational path) before and after the Renshi Taiwan textbook reform. Using nationally representative survey data from the Taiwan Social Change Survey (TSCS), I find, in line with my theoretical expectations, that promoting a narrower and more exclusive form of national identification reduces pro-immigrant attitudes. These results confirm the importance of taking into account educational content, and not just educational attainment, when examining the effect of education on anti-immigrant attitudes.

My paper makes two important contributions. First, it contributes to the long-standing literature on national identity formation and exclusionary attitudes towards immigrants by highlighting the role that education plays in promoting different types of nationalist narratives (Brubaker, 1992; Hiers, Soehl and Wimmer, 2017; Feinstein and Bonikowski, 2019). The more students are exposed to content that encourages an exclusive form of national identification, the less that education is effective at attenuating hostility towards immigrants. With the growing concern about the prominence of nationalistic narratives in school curricula and textbooks across many countries such as Hungary, Japan, Scotland, and the United States (Goldstein, 2020; Feinstein and Bonikowski, 2019; Grever and Van der Vlies, 2017; Morris, Shimazu and Vickers, 2014), my paper suggests that emphasizing a narrower and more exclusive form of national identification is likely to increase outgroup hostility.

Second, my paper contributes to the growing literature on the causal effect of education on anti-immigrant sentiment by challenging the widespread belief that increased education always reduces anti-immigrant attitudes. Scholars have recently begun to identify the causal effect of education on individual attitudes, utilizing experimental variation in access to additional schooling (Friedman et al., 2016; Cavaillé and Marshall, 2019). However, these studies mostly focus on educational attainment, i.e., the level of completed education or years of schooling. My work not only departs from, but extends, the existing literature by illustrating the important role of educational content. It highlights that the effect of educational attainment on individual attitudes is dependent on the nature of educational content. As such, my paper provides a more nuanced understanding of the causal pathway by which education matters. 


\section{Education and Attitudes Towards Immigrants}

Over the past two decades, studies have explored how individual-level characteristics such as educational attainment (Cavaillé and Marshall, 2019), religiosity (Bloom, Arikan and Courtemanche, 2015), and economic skill level (Mayda, 2006; Scheve and Slaughter, 2001) affect attitudes towards immigrants. While there is considerable debate about the precise impact of most of these individual-level characteristics, there seems to be a growing consensus that educational attainment is positively associated with less anti-immigrant sentiment (Hainmueller and Hopkins, 2014; Hainmueller and Hiscox, 2007, 2010). ${ }^{1}$

According to the existing literature, there are two possible pathways by which education is thought to affect attitudes towards immigrants. The first sees education increase an individual's skill levels, thereby reducing any fear of economic competition from immigrants (Mayda, 2006; Scheve and Slaughter, 2006; Shayo, 2009). The idea with this pathway is that highly educated natives show less hostility towards immigrants than less educated natives because they do not have to directly compete in the economic sphere with immigrants who are mostly expected to be low-skilled. The second pathway focuses on the specific content taught in the education system and how this directly affects attitudes towards immigrants. The argument here is that educational content promoting tolerance and open-mindedness leads to a reduction in anti-immigrant attitudes (Hainmueller and Hopkins, 2014). The expectation is that as individuals stay in the education system longer, they are more exposed to this core value and therefore more likely to internalize it.

The skill acquisition pathway leads to the unconditional prediction that higher levels of education will reduce hostile attitudes towards immigrants. In contrast, the explanation underpinning the educational content pathway produces a conditional prediction; namely that education decreases anti-immigrant sentiment but only when educational content promotes tolerance. To date, existing empirical studies have not examined the implicit conditionality at the theoretical core of the educational content pathway. This is important because recent studies have begun to question whether increased educational attainment always leads to

\footnotetext{
${ }^{1}$ An exception is Lancee and Sarrasin (2015), who find little evidence that educational attainment affects attitudes towards immigrants in Switzerland.
} 
more inclusive attitudes (Surridge, 2016; Henry and Napier, 2017). In this paper, I argue that educational content can promote either a broad and inclusive vision of national membership or a narrow and exclusive one. Educational content that promotes a narrower and more exclusive form of national identity should lead to more negative attitudes towards immigrants.

\subsection{Education, Nationalism, and Anti-immigrants Attitudes}

Nationalism is the social practice of identifying oneself with a nation-state and adhering to national symbolic boundaries (Bonikowski and DiMaggio, 2016). Existing research explores how political entrepreneurs strategically use narratives to create a sense of national identity and encourage attachment to a collective identity in order to secure and legitimize their power (Paglayan, 2021; Liu and Ma, 2018; Wimmer, 2013; Anderson, 2006; Weber, 1976). Many studies have shown that a government-led national curriculum is one of the most effective tools for constructing a sense of national identity (Idris et al., 2012; Darden and Grzymala-Busse, 2006; Hardwick, Marcus and Isaak, 2010). As an example, Cantoni et al. (2017) find that the introduction of a set of new politics textbooks in China's high school curriculum between 2004 and 2010 led students to manifest more favorable political attitudes towards the Chinese government.

The education system is especially effective at forging a particular sense of national identity because of its ability to deconstruct any existing identity and replace it with a newly defined identity (Bereketeab, 2020). When it comes to national identity formation, scholars of nation-building have identified two primary approaches by which political actors define who is included in the nation and who is not: (i) exclusive and (ii) inclusive. Scholars often employ slightly different terms for these two broad types of nationalism. For example, some refer to civic versus ethnocentric nationalism (Smith, 2005), some to individualistic versus collectivistic nationalism (Greenfeld, 1992), some to jus soli versus jus sanguinis nationalism (Brubaker, 1992), and others to voluntaristic versus cultural nationalism (Kohn and Calhoun, 2017). While these various classifications of nationalism differ from each other in several important ways, they all share the similar idea that a country's type of nationalism can be classified based on the degree to which the boundaries between an ingroup 
and outgroup are deemed inclusive or exclusive. While often presented in binary terms, it is important to recognize that the different approaches to national identity formation really capture a continuum, with what we might call 'extreme inclusiveness' at one end and 'extreme exclusiveness' at the other. ${ }^{2}$ Not only do countries sit at different points along this continuum but they can also seek to move along it by promoting more inclusive or more exclusive approaches with respect to who is included in the nation.

A narrow and exclusive form of nationalism tends to use more objective and less flexible criteria to classify individuals into different identity categories. This means that individuals have less control over whether they belong to a nation or not (Keating, 1997). In this sense, national membership is seen as something that is exclusive to those individuals who share certain inherent attributes, often related to things such as a particular ethnicity, place of birth, national ancestry, or religion. In contrast, a broad and inclusive form of nationalism typically emphasizes the flexibility and constructed nature of identity categories. Identity categories are not fixed and individuals have greater ability to choose to identify with an identity category of their choice. This means that membership in the national community is more open to individuals who share a self-conceptualized identity that potentially encompasses various characteristics (Van Heelsum and Koomen, 2016). Examples of such criteria may include adherence to the laws and values of a country or simply residential status.

Several studies suggest that when membership in a national community is conceptualized based on a narrower and more exclusive identity, such as language, ethnicity, religion, or race, it can trigger nationalist sentiment and exacerbate tensions with those who are excluded from the national community (Bonikowski, 2016; Brubaker, 1992). Because utilizing an inherent feature narrows the scope of nationhood to only those who share the same characteristic, outsiders who do not share the necessary characteristics are perceived as unfit for membership in the national community. Outgroup members will be seen as a threat to the exclusivity and relative homogeneity of the native-born population. A consequence is that ingroup attachment is likely to be associated with fear and hostility towards outgroup members. In

\footnotetext{
${ }^{2}$ In line with this, several scholars have criticized the 'binary' classification of national identity for its overemphasis on ideal types and its failure to recognize the full complexity of national identity formation (Tamir, 2019; Van der Zwet, 2015; Kuzio, 2002)
} 
other words, defining membership in terms of a narrower set of less malleable characteristics leads members to hold more hostile attitudes towards outsiders (Brewer, 2007). In contrast, identifying the national community in terms of broader and more inclusive identities can lead to a less conflictual relationship with outsiders who do not share the common identity. If national membership is conceptualized by voluntary allegiance to the principles for which the state stands, then national membership is more open to outsiders because they may one day become members of the political community (Hiers, Soehl and Wimmer, 2017; Feinstein, 2016). As a result, ingroup attachment does not necessarily translate into fear, hatred, or aggression towards outgroup members.

Education matters for attitudes towards immigrants because it affects how people think about national identity and who can be a member of the national community. When educational content promotes a narrower and more exclusive approach to national identification, immigrants are viewed as outsiders who jeopardize the exclusiveness and homogeneity of the national community (Brand, 2014). This leads to an increase in anti-immigrant attitudes. In other words, an increased emphasis on a narrow and exclusive form of national identity is expected to produce higher levels of anti-immigrant attitudes (Brewer, 2007; Sides and Citrin, 2007; Sniderman, Hagendoorn and Prior, 2004). In line with this, Pehrson, Vignoles and Brown (2009) find that anti-immigration sentiment is higher in countries where national membership is defined in terms of a common ancestry and common place of birth than where it is a matter of common citizenship. I build on this research by examining whether educational content that promotes a narrower and more exclusive approach to national identification results in increased anti-immigration attitudes.

Note that this does not necessarily mean that the opposite is true; that is, that a broader and more inclusive approach induces more favorable attitudes towards immigrants. It is possible that one can conceptualize national belonging in terms of self-allegiance to a given nation and, at the same time, show exclusionary attitudes towards immigrants. For example, some may perceive that immigrants are less capable of committing to the host country's political values than natives due to their inherent cultural disposition (Tonkens and Duyvendak, 2016). Along these lines, a recent study by Simonsen and Bonikowski (2020) provides evidence that 
the impact of inclusive criteria for nationhood on anti-immigrant attitudes is mixed - they are negatively correlated in most countries, yet positively associated in Northwestern Europe. Thus, it may be the case that educational content that promotes an inclusive approach to national identity will have little to no effect on anti-immigrant attitudes. The important point here is that a narrower and more exclusive approach to national identification is expected to promote more exclusionary attitudes towards outsiders than a broader and more inclusive approach and, as a result, we should see a significant difference in anti-immigrant attitudes when one approach is emphasized more than the other.

Educational Content Hypothesis: Educational content that promotes a narrower and more exclusive approach to national identification increases anti-immigrant attitudes compared to educational content that promotes a broader and more inclusive approach to national identification.

\section{The Case of Taiwan}

While my theory is quite general, identifying the causal effect of educational content is difficult. We, as analysts, are not in a position to randomly assign different educational content that varies in its approach to national identity formation to different students in a country. The best we can do is identify a real-world situation that allows a quasi-experimental design (Campbell and Stanley, 1966; Achen, 1986). Along these lines, I test my hypothesis by leveraging a 1997 education curriculum reform in Taiwan that allows me to examine the causal effect of educational content on attitudes towards immigrants. This particular textbook reform is appropriate for testing my theoretical claim because it included major changes in how Taiwanese identity was portrayed, especially as it relates to national culture, history, and territory. In September 1997, the Taiwanese government introduced the Renshi Taiwan junior high textbooks on history, geography, and society for secondary education. The new textbooks provoked a heated debate at the time because of their emphasis on making a clear distinction between Taiwanese and Chinese national identity (Su, 1998; Corcuff, 2013). In effect, the textbook reform introduced a narrower and more exclusive understanding of what 
it meant to be Taiwanese. This is not to claim that the Taiwanese government deliberately introduced the textbook reform in order to encourage more hostile attitudes to outsiders. I simply claim that there is a theoretical basis for thinking that the educational content promoted by this reform was likely to lead to an increase in anti-immigrant sentiment as a side-effect of enhanced exclusionary attitudes encouraged by the new educational content.

\subsection{Background of the Renshi Taiwan Textbook Reform}

When Chinese Nationalists fled to Taiwan in 1949, the nationalist party, the Kuomintang (KMT), worried that the "Chineseness" of the people in Taiwan might have been weakened by a series of historical events such as the February 28 massacre, also known as the 228 incident (Wang, 2017), by the KMT-led Chinese government in 1947. To secure the legitimacy of its rule, the KMT used the education system to promote a Taiwanese national identity with a strong Chinese consciousness (Zhongguo yishi) and a desire for unification with the Chinese mainland (Yinan, 2014). In this sense, Taiwanese national identity was portrayed as part of a broader and more inclusive Chinese identity.

As the demand for democratization grew in the late 1980s, the use of the national education system to promote Chinese-oriented narratives became increasingly problematic. Eventually, in 1995, the Ministry of Education and the National Institute of Compilations and Translations agreed to promote a narrower and more distinct Taiwanese identity by revising the textbooks used in schools (Corcuff, 2013). A new commission for editing new junior high school textbooks was established and put in charge of writing three manuals for the Renshi Taiwan courses. The Renshi Taiwan textbook series consisted of three subjects: history, geography, and society. Designed for the first year of junior high school, the textbook reform was implemented nation-wide. The first entering cohorts to study under the new textbooks were those who entered junior high school after September 1997. Students in the older grades (the second and third year of junior high school in 1997) would not have studied the new textbook because the High School Entrance Exam to proceed to senior high school for these older cohorts was based on the old textbooks.

As the first standalone school subject that promotes local knowledge of Taiwan, the 
new Renshi Taiwan textbooks shifted from the official promotion of a uniform vision of Chineseness to an increasing recognition of a narrower and more distinct Taiwanese identity. The de-Sinitized discourse in the textbooks paved the way for a new "nationalized" narrative with respect to Taiwanese identity (Hsiau, 2021; Wang, 2005). In particular, the changed national texts on history, geography, and society redefined the national territory based on a common historical and ancestral ground and explicitly sought to highlight the contributions of the aboriginal people to contemporary Taiwanese culture.

The promotion of a narrower and more exclusive form of national identification through the Renshi Taiwan textbooks was likely motivated by a desire to eschew Chineseness rather than an impulse to encourage an inherently ethnic vision of Taiwanese identity. In this sense, the Taiwanese government probably viewed the promotion of a more distinct Taiwanese identity simply as a way of securing greater political independence from mainland China. This fits with research on Eastern Europe in which scholars have noted how more exclusive aspects of nationalism were strategically promoted by various governments to help legitimize national belonging and gain political economy after both the collapse of the Austro-Hungarian Empire in 1918 and the Soviet Union in 1991 (Krastev, 2017; Kupchan, 1995).

\subsection{Changes in Renshi Taiwan Textbooks}

The changes in the Renshi Taiwan textbooks sensitized students to a different form of national identification that reimagined how the Taiwanese nation was connected to its territory. The content of the textbooks before the reform emphasized a broader Chinese territory, encompassing various territories and ethnic groups. Regardless of the differences in race, religion, language, and culture, everyone within the Chinese national territory was described equally as Chinese. It also sought to build a sense of national pride and common identity by emphasizing a broader political connection with China and by encouraging a strong empathy towards national tragedies in mainland China's past (Su, 2006, 1998). Here, aspects of national boundary were attributed to symbolic historical figures and traditions, especially those of the Han Chinese. In contrast, the reformed textbooks after 1997 allocated a great amount of time to promoting a narrower and more exclusive form of national identity. They 
describe Taiwan as a cultural, historical, and geographic entity distinct from China (Corcuff, 2013). In doing so, the national boundary of Taiwan is defined based on ancient ties to the land, emphasizing Taiwanese aborigines in the Penghu, Kinmen, and Matsu islands, i.e., "four major ethnic groups" (四大族群), as well as migrants from mainland China in the 1660s, i.e., “new immigrants from mainland China” (外省人). In other words, the new textbooks promoted a stronger national identification with the territory of Taiwan based on historical roots and territorial origins, whereas the old textbooks emphasized political identification with the state of China based on the belief that the people of Taiwan all belong to the same 'Chinese' group.

The shift in focus from a broader Chineseness to a narrower and more distinct Taiwanese identity is clearly shown in the learning objectives of the Renshi Taiwan textbook series. One of the objectives of the Society textbook was to "...identify with Taiwanese society, cherish existing achievements, reflect on social issues, and create a beautiful new society" As another example, the goal of the History textbook was "to guide students to understand the historical facts of the development of Taiwan by the ancestors of various ethnic groups, so as to cultivate the spirit of unity and cooperation, the sentiment of love for the community and the nation, and the vision of the world, and strengthen the students' understanding of Taiwan's cultural assets, knowing to cherish and love them." ${ }^{3}$ In other words, the new textbooks emphasized a specific Taiwanese identity that was defined by a more restrictive native-born status, ancestry, and history based on a narrower territorial definition. In contrast, the old textbooks focused on establishing Chinese identity by promoting a commitment to political institutions, i.e., "China."

More specific examples of differences between the new Renshi Taiwan textbooks and the older pre-reform textbooks are shown in Table 1. The most noticeable changes are made in the description of the national territory, ethnic groups and national origins, and national history. In particular, the new textbooks emphasize the national territory of Taiwan as separate from mainland China. While Taiwan was described merely as a province of mainland China in the old textbooks, the territory of Taiwan is more clearly focused on the island of Taiwan,

\footnotetext{
${ }^{3}$ See Online Appendix A for the excerpts showing the original text on these objectives.
} 
including the outlying islands of Penghu, Kinmen, and Matsu, in the new Renshi Taiwan textbooks.

Table 1: Comparison of the Old and the New Junior High Textbooks in Taiwan.

\begin{tabular}{|c|c|c|}
\hline Description & Old textbooks & Renshi Taiwan textbooks \\
\hline Territory & $\begin{array}{l}\text { A chapter introducing "Our Territory" } \\
\text { stated "Taiwan is located in the southeast } \\
\text { of our country," where our country } \\
\text { denoted mainland China, Taiwan, Penghu, } \\
\text { Kimen, and Matsu island. }\end{array}$ & $\begin{array}{l}\text { The description of the territory states that } \\
\text { "Taiwan is located to the southeast of mainland } \\
\text { China." }\end{array}$ \\
\hline \multirow[t]{2}{*}{$\begin{array}{l}\text { Ethnic } \\
\text { origins }\end{array}$} & \multirow[t]{2}{*}{$\begin{array}{l}\text { "China" was introduced as an } \\
\text { amalgamation of different ethnic groups } \\
\text { within the national borders. }\end{array}$} & $\begin{array}{l}\text { The term "the Chinese" was replaced with } \\
\text { "Hanren" (Han ethnicity) to distinguish the } \\
\text { mainland Chinese from the Taiwanese who are } \\
\text { living in Taiwan. }\end{array}$ \\
\hline & & $\begin{array}{l}\text { "Indigenous people, Minnan people, Hakka } \\
\text { people, and people from other provinces (new } \\
\text { residents) make up the four major ethnic groups } \\
\text { in Taiwanese society today." (Renshi Taiwan } \\
\text { society textbook, p.3) }\end{array}$ \\
\hline $\begin{array}{l}\text { National } \\
\text { History }\end{array}$ & $\begin{array}{l}\text { Only three short chapters were devoted to } \\
\text { Taiwanese history since the } 1945 \text { takeover. } \\
\text { Most of the emphasis was put on } \\
\text { mainland Chinese history and culture. }\end{array}$ & $\begin{array}{l}\text { "The history of Taiwan was divided into } \\
\text { different eras such as the prehistoric era, the } \\
\text { period of international competition, the period } \\
\text { of Zheng's rule of Taiwan, the era of the Qing } \\
\text { Dynasty, the period of Japanese colonial rule, } \\
\text { and the Republic of China in Taiwan." (Renshi } \\
\text { Taiwan history textbook, p.1). }\end{array}$ \\
\hline
\end{tabular}

Note: Descriptions of the content are based on Lui, Hung and Vickers (2013), Corcuff (2013), and the old history textbooks published in 1996, and the Renshi Taiwan textbooks published in 1997.

The emphasis on the territory of Taiwan extends to an increased emphasis on the national community within the newly defined territorial boundary. For example, when describing ethnic origins and cultural identity, the old textbooks defined 'Chinese' as the groups that constitute the Chinese nation, including the Han, Manchus, Mongolians, Moslems, Tibetans, and Taiwanese aborigines (Lui, Hung and Vickers, 2013). While different ethnic groups were recognized, they were described as the same Chinese people who have assimilated into a common Han Chinese group, sharing more than 5,000 years of history. In contrast, the new textbooks made a clear distinction between the Han Chinese and Taiwanese aborigines who are of a Malayo-Polynesian descent. They described the origin of Taiwanese ethnic groups as follows:

As early as 50,000 years ago, there were Changbin people from the late Paleolithic age living in Taiwan. Later, through the Neolithic Age and the Metal Age, 
people from different culture settled in Taiwan. These people from prehistoric times are closely related to the aboriginal peoples of Taiwan now (Renshi Taiwan history textbook, p.1).

The differences in the recognition of national origins affected the portrayal of national history in the old and new textbooks. Before the textbook reform in 1997, national history was highly focused on Han Chinese discourse, neglecting distinct historical events that occurred on the island of Taiwan. For example, the history subject was taught in a way where students would spend the first two years of junior high school learning about China and the last year about the wider world. Under the old textbooks, Taiwan is first mentioned very briefly in the latter part of the second volume out of three history textbooks dedicated to describing Han Chinese historical discourse, when discussing how Zheng Chenggong came to Taiwan after being defeated by the Qing dynasty. After the curriculum change, however, junior high school students spent their first year learning about Taiwanese history with the Renshi Taiwan textbooks, only after which did they learn about Chinese and World history (Lui, Hung and Vickers, 2013). Also, under the new textbooks, the stages of Taiwanese history were classified based on the historical events on the island of Taiwan, shifting attention from the Han-centered history of ancient Chinese dynasties.

In addition, the Renshi Taiwan history textbook described Taiwan inhabitants as Taiwanese, denoting four specific groups of Taiwanese aborigines, Minnan, Hakka, and Waishengren, who are residents in the island of Taiwan. The people on mainland China were described as Han Chinese, the dominant majority in mainland China. Table 2 shows the frequency of words distinguishing Taiwan (or Taiwanese) from mainland China (or Chinese) in the new history textbook. One can see in the table that Taiwanese identity was emphasized with the significant use of the term 'Taiwan' or 'Taiwanese.' Also, the new textbook used the term 'mainland China' or 'Han Chinese' rather than 'Chinese,' trying to minimize the connection between China and Taiwan.

In sum, the content from the old and the Renshi Taiwan textbooks provides evidence that the new textbooks anchored Taiwanese identity in a narrower and more exclusive national boundary and ethnic origin than the old textbooks. In addition, the description of Taiwanese 
Table 2: Counts of Words in the Renshi Taiwan History Textbook.

\begin{tabular}{llc}
\hline \hline \multicolumn{1}{c}{ Words in English } & \multicolumn{1}{c}{ Words in Chinese } & Count \\
\hline Taiwanese & 臺灣人 (Taiwanren) & 11 \\
Taiwan & 臺灣 (Taiwan) & 396 \\
Chinese & 中國人 (Zhongguoren) & 0 \\
Han Chinese & 漢人 (Hanren) & 52 \\
China & 中國 (Zhongguo) & 41 \\
Mainland China & 中國大陸 (Zhongguo dailu) & 28 \\
Chinese Communist Party & 中共 (Zhonggong) & 14 \\
Republic of China & 中華民國 (Zhonghua minguo) & 15 \\
\hline \hline
\end{tabular}

Note: The Renshi Taiwan textbooks were an addition to, not an replacement of, the curriculum of junior high school students. Hence, students would have been exposed to these words only under the new textbooks, but not under the old textbooks.

national history was focused on specific groups within a narrowly defined geographic and cultural boundary. Consequently, the narratives found in the Renshi Taiwan textbooks promoted a narrower and more exclusive definition of Taiwanese identity than had previously been the case. Note that I am not necessarily arguing that the new Renshi Taiwan textbooks promoted a highly exclusive form of Taiwanese identity in an absolute sense. I am simply arguing that they promoted a narrower and more exclusive vision of Taiwanese identity than had been the case in the past. This is what is required to test my hypothesis.

\section{Empirical Strategies}

In this section, I describe my identification strategy to estimate the causal effect of the Renshi Taiwan textbook reform on anti-immigrant attitudes. I use a difference-in-differences design that leverages variation in the intensity with which different sets of students consumed the information in the new textbooks. Specifically, I compare the anti-immigrant attitudes of individuals on the academic path who consumed the new educational content in detail to those of individuals on the vocational path who are much less likely to have consumed the new educational content. My theory predicts that individuals who extensively studied the new educational content promoting a narrower and more exclusive form of Taiwanese identity will 
show higher levels of anti-immigrant attitudes than those who studied the content in the old textbook encouraging a broader Chinese and more inclusive form of national identification.

\subsection{Data and Measures}

To explore the effect of educational content on anti-immigrant attitudes in the context of Taiwan's textbook reform in 1997, I use five waves from the Taiwan Social Change Survey (TSCS): 2005, 2008, 2010, 2013, and 2015. The TSCS is a nationally representative survey of respondents aged 18 years and older in Taiwan. ${ }^{4}$ I focus on these particular five waves of the TSCS because they include a common question about anti-immigrant attitudes. There are two advantages of using the TSCS data over other possible sources of survey data. The first is that the TSCS asks respondents about their birth year and month. This is important because it allows me to identify a respondent's exact school cohort and hence whether they were exposed to the new Renshi Taiwan textbooks or not. The second is that the TSCS records both a respondent's highest level of education and their educational path (academic or vocational). This is important because knowing the academic path of the respondent is what allows me to estimate the causal effect of educational content by comparing the intensity with which the Renshi Taiwan textbooks were consumed.

I restrict my sample to adults born between September 1975 and August 1989. This is equivalent to limiting the sample to school cohorts that entered junior high school between 1988 and 2001. This temporal restriction was imposed to correspond to the period in which the Renshi Taiwan textbooks were used. In 2001, the Ministry of Education pulled out of the business of writing junior high school textbooks completely, replacing the Renshi Taiwan series with the Social Studies in the New Grade 1-9 curriculum (Chen and Huang, 2017). In addition, the High School Entrance Exam was replaced by the Basic Competence Test (BCT) for junior high school students for admission to senior high schools. The BCT admission system put less emphasis on the absorption of the material in school textbooks, hence potentially reducing the impact of educational content. Considering this change, the

\footnotetext{
${ }^{4}$ The earliest survey year that I could have included is the 2003 wave. This wave contains the very youngest cohort (those born in 1984) who would have studied the Renshi Taiwan textbooks. However, this particular wave of the survey does not include all of the necessary measures, such a respondent's place of birth, that I include in my upcoming analyses.
} 
school cohort who entered junior high school after 2001 may not have been exposed to or meaningfully studied the Renshi Taiwan textbooks in a similar way to those who entered junior high school before 2001. Therefore, I restrict my sample to include school cohorts up to 2001, or equivalently, to respondents born between September 1988 and August 1989 (aged 8-9 in 1997).

It is possible that the effect of compulsory schooling does not persist throughout someone's life. Individuals go through certain life experiences as they grow up, such as getting a job, meeting people from diverse backgrounds, and starting a family. These experiences mean that it is unlikely to be the case that the effect of educational content persists through the course of someone's life. To account for the possible dilution of any education effect, I focus on a cohort group whose age ranged from 13-14 to 21-22 in 1997 when considering those who studied the old textbook. This age restriction helps to balance potential life experiences between the comparison and treatment groups. Students in the comparison group (respondents who were just old enough to study the old textbooks) will be relatively close in terms of life experience to the treatment group (respondents who studied the new textbooks) in that respondents in both groups would be mainly focused on school life instead of job experiences or other social interactions. Lastly, I only include individuals whose highest level of education is at least junior high school. Those who did not graduate from junior high school are highly unlikely to have had an opportunity to be exposed to the new textbook series. These restrictions leave me with a sample of 2,380 respondents. Online Appendix B provides more descriptive information about my sample.

My hypothesis requires an outcome variable that measures attitudes towards immigrants. My dependent variable, Pro-Immigrant Attitudes, captures the extent to which respondents report positive attitudes towards immigrants. This variable is based on a survey question where respondents are asked whether they would like to see an increase or decrease in immigrants to Taiwan. It is coded on a scale from 1 to 5 , where higher numbers indicate a more favorable attitude towards immigrants.

To capture educational content, I use a binary variable, New, that equals 1 if a respondent studied the new Renshi Taiwan textbooks and 0 if they studied the older textbooks. Academic 
measures variation in the intensity with which the new textbooks were consumed. As I have indicated, I do not expect the effect of the new content to be the same for all students. This is because some students, specifically those on the academic track, have a stronger incentive to pay attention to the textbook content than students on the vocational track. One way to think about this is that a student's academic path serves as a proxy for the intensity with which students consumed educational content. The requirements to get into vocational institutions often do not emphasize school textbooks and tests as academic institutions do. In fact, in Taiwan until 2001, the only way for students to enter academic senior high school was to get a good score on the High School Entrance Exam, which was based on the subjects taught in junior high school (Huang, 2019). As a result, students on the academic path devote substantial time to improving their scores and thus their chances of winning a place in a good academic high school. In contrast, the emphasis on the exam was lower for students taking the vocational path because a majority of vocational senior schools admit students based on their own admission program rather than their knowledge on an exam.

Importantly, there is no reason to think that the choice of educational path is affected by the new educational content in the Renshi Taiwan textbooks. The High School Entrance Exam covers a multitude of subjects such as Chinese literature, mathematics, science, social science, and English (Huang, 2019). As a result, the material from the Renshi Taiwan textbooks are only part of that covered on the exam. Also, the choice of educational path is fairly stable because students choose their path in their third year of junior high school, which makes it hard for students to change their path in the middle of the school year as it is already too close to the High School Entrance Exam. Most importantly, the choice of educational path is closely tied to a student's future outlook - which university they wish to attend or what jobs they want to have in the future. Thus it is unlikely that the new textbooks were a critical factor in determining or changing a student's educational path. Academic is coded 1 if a student is on the academic path and 0 if they are on the vocational path. Online Appendix B discusses the construction of this variable in more detail.

In addition to these variables of interest, I also include individual-level covariates to capture things such as gender, employment status, marital status, college education, self- 
evaluated social class, and parents' educational path. Gender, employment status, marital status, and college education are all dichotomous variables, where 1 indicates being female, employed, married, and having completed college or higher. Self-reported social class is coded with 10 categories from the top (10) to the bottom (1). Online Appendix C presents the summary statistics for the overall sample as well as for the pre- and post-reform cohorts.

\subsection{Identification Strategy}

I identify the causal effect of educational content on anti-immigrant attitudes with a differencein-differences design that utilizes the fact that exposure to the reformed textbook content varied by a respondent's date of birth and educational path. The first source of variation, the date of birth, decides who was exposed to the new Renshi Taiwan textbooks. The second source of variation comes from the respondent's educational path. Those who wished to proceed to higher education and were therefore on the academic path had greater motivation to study the textbook content because they had to meet a minimum required score on the High School Entrance Exam to be admitted to public academic high schools (Huang, 2019). ${ }^{5}$

Using this variation, I estimate the change in the attitudes towards immigrants by each educational path before and after the introduction of the textbook reform. Specifically, I use regression to estimate the following difference-in-differences model,

$$
\begin{aligned}
\text { Pro-Immigrant Attitudes }_{i t g}= & \beta_{0}+\beta_{1} \text { Academic }_{g}+\beta_{2} \text { New }_{t}+\beta_{3}\left(\text { Academic }_{g} \times N e w_{t}\right) \\
& +\gamma\left(C_{i t g} \times N e w_{t}\right)+\delta C_{i t g}+\boldsymbol{X}_{i t g}^{\prime} \boldsymbol{\delta}+\varepsilon_{i t g}
\end{aligned}
$$

where Pro-Immigrant Attitudes ${ }_{i t g}$ is a preference for increased immigration on the part of

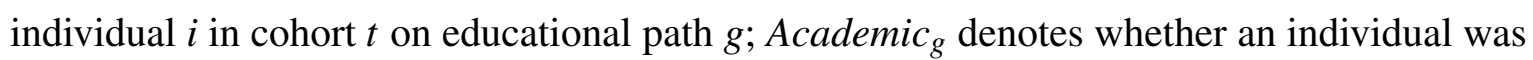

\footnotetext{
${ }^{5}$ Besides the introduction of the new textbooks, there are a number of events that could be have affected anti-immigrant attitudes after 1997, such as the handover of Hong Kong in 1997, the first direct presidential election in 1996, and the nation-wide earthquake in 1999 (Hur, 2020). However, the difference-in-differences methodology that I employ remains appropriate because these exogenous events will most likely have affected the treated and comparison (untreated) groups equally. It is hard to imagine that junior-high students on the academic or vocational path would have been affected differently by those events such that one group would be more pro-immigrant than the other. Not only would their interests in socio-political issues have been weak given that they could not vote, but their educational path does not generate different exposure to these common shocks.
} 
on the academic path or not; and Newt indicates whether the individual studied the new Renshi Taiwan textbooks or not, where $N e w_{t}=1$ if $t \geq$ September 1997 and 0 otherwise. The interaction term between Academic and New represents the treatment. As a result, $\beta_{3}$ is the main estimate of interest because it captures the causal effect of the new educational content. This is because respondents are considered as treated if their junior school entry year comes after the introduction of the new Renshi Taiwan textbooks and they were on the academic path. By contrast, if a respondent's high school entry year was prior to the textbook introduction year or they were on the vocational path, they represent the comparison group where respondents are untreated.

I also include various individual-level covariates as well: $\boldsymbol{X}_{i t g}^{\prime}$ is a set of time-varying individual-level controls and $C_{i t g}$ is a time-invariant covariate (parents' educational path) that has a time-varying effect on pro-immigrant attitudes. The identification strategy assumes that the students who used the new textbooks would maintain the same difference in proimmigrant attitudes compared to those who used the old textbooks had it not been for the textbook change. This assumption will be violated if the effect of a covariate varies with time. In the context of this study, this means that there should be no confounders that affect pro-immigrant attitudes differently over time. Considering that students decide their educational path in their third year of junior high school rather than being assigned randomly, this assumption may be violated if there is a variable correlated both with the student's choice of educational path and any changes in their attitudes towards immigrants.

In this regard, one may suspect that the educational path of a respondent's parents might have a strong influence on their child's choice of educational path as well as attitudes towards immigrants. Studies show, for example, that parents exert a great influence over their children's choice of major because parents support their children's education expenses or because the children are familiar with their parents' careers and develop an interest in similar majors or professions (Ma, 2009; Sonnert, 2009). Also, a parent's educational path may be correlated with their intelligence and income level, which may have a significant effect on their children's intelligence and the choice of educational path - and consequently on the socio-political attitudes of their children (Rindermann and Ceci, 2018). Therefore, I control 
for the interaction between the introduction of the new textbooks that captures the time of intervention and the parents' educational path (Zeldow and Hatfield, 2019; Duflo, 2001).

In addition to these covariates, I also include several fixed effects: education level, school cohort, survey year, and region of education. Controlling for a respondent's education level and school cohort will help capture unmeasured time-invariant confounders. For example, an older cohort might have stronger anti-immigrant attitudes compared to a younger cohort because the older generation tends to be more conservative. Since the fixed effects control for unobserved characteristics that are unique to a cohort and group, the main variables of interest are able to isolate the effect of the change in the textbook content. In addition to the education level and school cohort, I include a respondent's region of education and survey year fixed effects to account for possible unobserved events that occurred in the region of education and the year the survey was conducted (Duflo, 2001). Robust standard errors are clustered by school cohorts $\times$ educational path. ${ }^{6}$

While the differences between the treatment and comparison groups do not pose a threat to validity in the difference-in-differences design, some researchers suggest using matching methods to improve the extent to which other than the treatment the treated and comparison groups are similar to one another (Chabé-Ferret, 2015). In line with this, I use propensity score matching to balance out differences in some key personal characteristics in the treatment and comparison groups (Rosenbaum and Rubin, 1983; Stuart et al., 2011). The adjustments using propensity scores create a dataset that contains individuals who are assigned to either the treatment or comparison group in such a way that they have a similar chance of receiving the treatment based on the key covariates (Imai and Ratkovic, 2014).

\section{Results}

Table 3 presents the results from my analysis using the original TSCS survey dataset and the matched dataset. Recall that the main estimate of interest is the coefficient on the interaction term between educational path (Academic) and the education cohort that received the Renshi

\footnotetext{
${ }^{6}$ While there is no consensus on how to select an appropriate level of clustering, some studies recommend using bigger and more aggregate clusters when possible (Cameron and Miller, 2015). In Online Appendix F, I show that my results are robust to using bootstrapped clustered errors as well as alternative clustering schemes.
} 
Taiwan textbooks (New). This is shown in the first row of the table.

Table 3: Renshi Taiwan Textbook Effects on Anti-Immigrant Attitudes.

\begin{tabular}{lcc}
\hline \hline & \multicolumn{2}{c}{ DV: Preference for increased number of Immigrants } \\
\cline { 2 - 3 } & $(1)$ & $(2)$ \\
& Original & Matched \\
\hline \hline Academic $\times$ New & $-0.228^{* * *}$ & $-0.196^{* *}$ \\
& $(0.064)$ & $(0.095)$ \\
Academic & $0.553^{*}$ & 0.480 \\
New & $(0.322)$ & $(0.379)$ \\
& 0.122 & 0.094 \\
Constant & $(0.100)$ & $(0.163)$ \\
& $2.494^{* * *}$ & $2.322^{* * *}$ \\
& $(0.596)$ & $(0.617)$ \\
Observations & 987 & 662 \\
R-squared & 0.171 & 0.176 \\
\hline \hline
\end{tabular}

Note: All models are estimated using ordinary least squares (OLS). Variables not shown include education level, cohort year, region of birth, and survey year fixed effects along with individual covariates such as gender, employment status, marital status, subjective social class, and high education (college graduate). Robust standard errors clustered by school cohorts $\times$ educational path are shown in parentheses.

$* p<0.1, * * p<0.05, * * * p<0.01$

As predicted, the coefficient on the interaction term is negative and statistically significant in both models. Based on the results from the original dataset, the magnitude of the interaction term coefficient suggests that being exposed to the new educational content results in a drop of 0.228 points in pro-immigrant sentiment. This decrease amounts to $22 \%$ of a standard deviation of the dependent variable. Alternatively, we can think that the consumption of the new textbook content reduces the preference for increased immigrants by about $5.7 \%$ in the answer scale. ${ }^{7}$ The results are similar for the matched dataset. The coefficient for the interaction term remains negative and statistically significant. Exposure to and consumption of the new textbook content leads to a decrease in the preference for more immigrants by $19.6 \%$ of a standard deviation, or by $4.8 \%$ in terms of the answer scale on the dependent variable. The results also hold when the effect of the new textbooks is estimated with only pre-treatment covariates for each dataset, instead of including both pre- and post-treatment

\footnotetext{
${ }^{7}$ Given that the answer scales for the dependent variable run from 1 (decrease a lot) to 5 (increase a lot), consuming educational content from the new Renshi Taiwan textbooks reduces pro-immigrant sentiment by $\frac{0.228}{4} \times 100=5.7 \%$.
} 
covariates. $^{8}$

The substantive magnitude of the estimated effect of educational content is not trivial if we compare it to previous findings on the effect of educational attainment on anti-immigrant attitudes. For example, Cavaillé and Marshall (2019) report that an additional year of schooling decreases their anti-immigration index by $20 \%$ of a standard deviation, which is close to the size of the reduction in the standard deviation of my dependent variable. In other words, my results suggest that educational content promoting a narrower and more exclusive form of national identification has a substantively meaningful negative effect on favorable attitudes towards immigrants.

My finding that educational content highlighting a narrower and more exclusive conceptualization of Taiwanese national identity reduces pro-immigrant attitudes is theoretically important in two particular ways. First, findings from this study reveal that the educational content effect remains well into later adulthood. One might argue that the effect of educational content persists at best into young adulthood because individuals before this age period do not have many opportunities to interact with diverse people or to broaden their experience. However, the main results based on the datasets surveyed from 2003 to 2015, a time period which is about 6 to 18 years after a respondent's exposure to the school textbooks, suggest that the role of educational content taught in schools may have a long-lasting impact on anti-immigrant attitudes. Second, I show that public attitudes can be affected by educational content that indirectly links to intolerant values. The suggested mechanism by which emphasizing a narrower and more exclusive form of national identification exacerbates anti-immigrant attitudes implies that educational content that does not directly engage with anti-immigrant narratives can still have a significant negative impact on attitudes towards immigrants. This is in line with recent evidence showing an indirect influence of national identity on attitudes towards refugees (Rosenzweig and Zhou, 2020).

\footnotetext{
${ }^{8}$ Some studies raise caution about including post-treatment covariates that are likely to be influenced by a treatment (Lechner, 2011). To account for potential bias stemming from such post-treatment time-varying controls such as employment status, marital status, subjective social class, and educational level, I estimate the effect of the new textbooks with pre-treatment controls as well as a full set of controls. The regression results, which are qualitatively similar, can be found in Online subsection E.1.
} 


\subsection{Is This just a China Story?}

Strengthening national identification through the study of new textbooks may not automatically stimulate exclusionary attitudes towards all out-groups. Rather, it may depend on whether respondents consider a specific immigrant's country of origin as a salient outgroup. Since the focus of the Renshi Taiwan textbooks was on creating a narrower and more distinct Taiwanese national identity separate from a broader Chinese identity, it is possible that respondents could have drawn their exclusive boundary specifically towards those who are from mainland China and not with respect to immigrants from other countries. My data allow me to partially get at this possibility by differentiating attitudes towards immigrants that come from different regions. Specifically, I am able to look at anti-immigrant attitudes towards immigrants who come from China, Southeast Asia, and Europe or America. The TSCS question of interest here is the following: If more and more people from [Country or Region of Origin] become citizens of Taiwan, do you think this is good or bad for Taiwan?

Table 4: The Effect of the Renshi Taiwan Textbooks on Attitudes towards Immigrants from Different Countries or Regions.

\begin{tabular}{lccc}
\hline \hline & \multicolumn{2}{c}{ DV: Good for Taiwan if people from [country or region] become citizen of Taiwan } \\
\cline { 2 - 4 } & China & $(2)$ & $(3)$ \\
& $-0.732^{* * *}$ & Southeast Asia & Europe or America \\
\hline \hline Academic $\times$ New & $(0.204)$ & $-0.440^{* *}$ & -0.358 \\
Academic & -0.839 & $(0.180)$ & $(0.250)$ \\
& $(0.822)$ & -1.084 & -0.661 \\
New & 0.301 & $(0.776)$ & $(0.676)$ \\
& $(0.470)$ & 0.364 & -0.161 \\
Constant & $6.054^{* * *}$ & $(0.501)$ & $(0.250)$ \\
& $(1.106)$ & $5.363^{* * *}$ & $5.748^{* * *}$ \\
Observations & 215 & $(0.974)$ & $(0.636)$ \\
R-squared & 0.250 & 216 & 215 \\
\hline \hline
\end{tabular}

Note: The analysis is based on the survey year of 2013 due to the unavailability of the relevant dependent variables in other survey years. All models are estimated using ordinary least squares (OLS). Variables not shown include education level, cohort year, region of birth, and survey year fixed effects along with individual covariates such as gender, employment status, marital status, subjective social class, and high education (college graduate). Robust standard errors clustered by school cohorts $\times$ educational path are shown in parentheses. $* p<0.1, * * p<0.05, * * * p<0.01$

While the results in Table 4 show that the effect of educational content on exclusionary attitudes is strongest for Chinese immigrants, they also show that it is not limited to Chinese 
immigrants. In fact, it extends to Asian immigrants in general. Compared to the students who studied the old textbooks, students who were exposed to and consumed the new textbooks exhibit statistically significantly more negative attitudes towards immigrants from China and Southeast Asia. It is worth noting that although the coefficient on the interaction term is not statistically significant for immigrants from Europe or America, it has the predicted negative sign and is of a similar magnitude to the interaction term coefficient from the model where we are looking at immigrants from Southeast Asia. Overall, the results shown in Table 4 indicate that this is not just a China story. Exposure and consumption of educational content promoting a narrower form of Taiwanese identity caused an increase in hostility towards immigrants in general.

\subsection{Validation Checks}

My hypothesis posits that educational content promoting a narrower and more exclusive approach to national identification increases anti-immigrant attitudes. This means that, absent the Renshi Taiwan textbook reform, the gap in the level of anti-immigrant attitudes of students on the academic and vocational educational paths would have remained similar over time. The left panel in Figure 1 indicates that students on the vocational path had much lower levels of support for immigration prior to the textbook reforms in 1997 than those on the academic path. The important thing to note, though, is that the gap in support for immigrants between the vocational and academic paths was fairly constant before the textbook reforms. As the shaded area in the left panel of Figure 1 indicates, the post-reform period is associated with a significant narrowing of the gap in attitudes towards immigrants. This is evidence that the textbook reform had a significant impact. Importantly, we see that the narrowing of the gap is primarily associated with those on the academic path lowering their support for immigrants. This supports the idea that the textbook reform had its effect on those on the academic path who actually consumed the educational content in the textbooks.

The constant difference between the treated and comparison groups before the introduction of the Renshi Taiwan textbooks can also be tested using placebo reform years. To assert that it was the textbook reform that increased anti-immigrant attitudes, there should not be a 
Figure 1: Trends in anti-immigrant attitudes (left) and Placebo Reform (right).
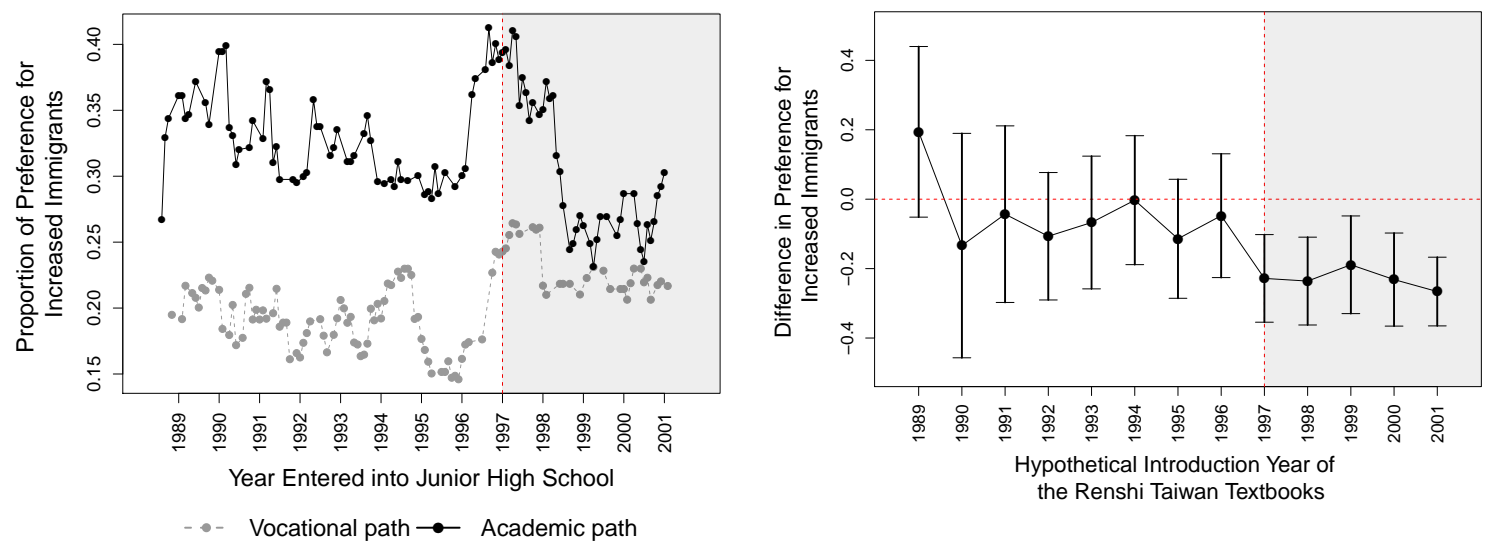

Note: The trend illustrates a 12-month moving average by educational path of a proportion of respondents who answered that they prefer an increased number of immigrants. The placebo reform shows the effects of new textbooks using hypothetical years of introduction. All regression coefficients are estimated using the same model in Table 3. The circle symbols represent the coefficients and the bars $95 \%$ confidence intervals.

significant difference between the academic path and the vocational path before the actual adoption year of 1997. To check this possibility, I plot the coefficients on the treatment term Academic $\times$ New based on the model used in Table 3 by moving the introduction year of the new textbooks. To do so, I consider only individuals who went into junior high school before 1997 and assign a hypothetical treatment as if the textbook had been introduced in a cohort-year $t$ rather than in 1997, where the cohort-year $t$ runs between 1989 and 1996. No students were actually exposed to the new textbooks under the placebo reform years, hence we should observe no significant textbook effect. I also assign the placebo introduction years after 1997 to show how the treatment effect evolves over time.

The right panel in Figure 1 clearly shows that the educational content effect only appears with the actual introduction of the Renshi Taiwan textbooks in 1997 and not before. The estimates before the year 1997 are not statistically different from zero, indicating that there is no significant textbook effect before the introduction of the Renshi Taiwan textbooks. After the new textbooks are introduced, the difference in attitudes towards immigrants between the two groups becomes significant. 


\subsection{Robustness Checks}

The pooled difference-in-differences estimates are robust to various potential concerns. The detailed results for robustness checks are available in Online Appendix F. First, I check whether the results are sensitive to the cohort range of the comparison group. To do so, I examine the estimates using different comparison groups from the original 9-year cohort range (aged from 13-14 to 21-22 in 1997): either a 5-year cohort range (aged from 13-14 to 17-18 in 1997) or a 13-year cohort range (aged from 13-14 to 25-26 in 1997). The resulting estimates of educational content effects are still negative and statistically significant. This further corroborates the findings from Table 3 that exposure to educational content promoting a narrower view of national identity causes respondents to become less favorable to more immigrants.

Second, in order to examine whether the results are sensitive to the time gap between the introduction of the Renshi Taiwan textbook series and the survey years, I re-estimate the model in Table 3 with different subsets: short-term and long-term. I find that the effect of educational content remains negative and statistically significant for respondents from the relatively short-term sample in which those who studied the Renshi Taiwan textbooks were 20-25 years old around the time of the survey. However, the effect attenuates in the long-term sample in which those who studied the Renshi Taiwan textbooks were 26-30 years old around the time of the survey. One potential explanation for the different results based on the survey time is interaction with diverse groups. As students get older, those who studied the new textbooks may have encountered people with "pro-immigrant" thinking in their life or interacted with immigrants in Taiwan in a pleasant way.

Third, I also compute standard errors clustered with a different method and at a different level. Researchers have increasingly realized that the typical use of cluster-robust standard errors may fail to successfully control for within-group dependence when the number of clusters is small, approximately fewer than thirty (Cameron, Gelbach and Miller, 2008). To confirm that the results are not driven by an inappropriate number of clusters, I re-analyze the model using the method of bootstrapping as an alternative method of obtaining clustered standard errors as well as employing a finer unit than the cohort year $\times$ education path by 
using the cohort year $\times$ education level. The results show that the standard errors increase when applying the bootstrap method and when clustered by cohorts $\times$ education level but do not have a substantive effect on the findings.

\section{Conclusion}

Existing research on anti-immigrant attitudes claims that higher levels of education are negatively associated with anti-immigrant attitudes, either because education directly shapes an individual to be more tolerant of other nationals or because education promises lower exposure to competition from incoming immigrant labor (Hainmueller and Hopkins, 2014). While these studies assume that education promotes tolerant values in its content, the validity of this assumption has recently been called into question (Surridge, 2016). My study contributes to existing studies by employing a rigorous empirical design that allows me to tease out the causal effect of educational content on attitudes towards immigrants. Furthermore, this paper expands the scope of analysis by examining the importance of different educational content. Educational content that promotes a narrower and more exclusive form of national identification is expected to lead people to hold more exclusionary attitudes.

Leveraging the Renshi Taiwan textbook reform that encouraged the formation of a narrower and more exclusive Taiwan-oriented national identity than had previously been the case, I examine the causal effect of educational content on anti-immigrant attitudes with a difference-in-differences design. I find that people who closely studied the Renshi Taiwan textbooks show stronger anti-immigrant attitudes compared to those who studied the old textbooks. This shows that anti-immigrant attitudes are not simply formed by education per se, but by the values promoted in educational content and by the consumption of such content. Educational content will vary from country to country and so we should not expect higher levels of education to necessarily be associated with more pro-immigrant attitudes. This suggests that we should be careful to take into account the modifying effect of educational content when examining the impact of educational attainment on anti-immigrant sentiment.

The theory and findings in this paper have several implications for explaining the increased 
use of education as a tool of indoctrination in many countries. First, educational content can influence not only preferences about the government (Cantoni et al., 2017), but also foreign cultures and people. My study provides more empirical evidence of the role of education in promoting nationalism (Liu and Ma, 2018). Second, the role of education in instilling certain values can be generalized to any country. Studies examining the causal effect of school curricula on public attitudes have focused predominantly on authoritarian regimes such as China, implicitly assuming that the need for utilizing education in such a way would be greater for authoritarian leaders due to their inherent incapacity to monitor their citizenry (Gerschewski, 2013). However, educational content has been used by leaders in democratic countries as well. In fact, there has been a worldwide push to develop a formal national curriculum, from Australia which endorsed its first national curriculum in September 2015 to Brazil which sanctioned a reformed national curriculum in December 2018.

Overall, my analysis suggests that higher education may not be a panacea for reducing hostility towards immigrants. Higher education institutions are not places that automatically secure free and liberal values. If they fail to provide an adequate environment to nurture tolerance, we can observe growing prejudice despite someone's level of education. My finding implies that it is particularly important to recognize the power of educational content that can encourage certain values and attitudes. 


\section{References}

Achen, Christopher H. 1986. The Statistical Analysis of Quasi-Experiments. Berkeley, CA: University of California Press.

Anderson, Benedict. 2006. Imagined Communities: Reflections on the Origin and Spread of Nationalism. London: Verso.

Bereketeab, Redie. 2020. "Education as an instrument of nation-building in postcolonial Africa." Studies in Ethnicity and Nationalism 20(1):71-90.

Bloom, Pazit Ben-Nun, Gizem Arikan and Marie Courtemanche. 2015. "Religious social identity, religious belief, and anti-immigration sentiment." American Political Science Review 109(2):203-221.

Bonikowski, Bart. 2016. "Nationalism in settled times.” Annual Review of Sociology 42:427_ 449.

Bonikowski, Bart and Paul DiMaggio. 2016. "Varieties of American popular nationalism." American Sociological Review 81(5):949-980.

Brand, A. Laurie. 2014. Official Stories: Politics and National Narratives in Egypt and Algeria. Stanford: Stanford University Press.

Brewer, B. Marilynn. 2007. The Social Psychology of Intergroup Relations: Social Categorization, Ingroup Bias, and Outgroup Prejudice. New York: Guilford Press.

Brubaker, Rogers. 1992. Citizenship and Nationhood in Germany and France. Cambridge, Mass: Harvard University Press.

Cameron, A. Colin and Douglas L. Miller. 2015. "A practitioner's guide to cluster-robust inference.” Journal of Human Resources 50(2):317-372.

Cameron, A. Colin, Jonah B. Gelbach and Douglas L. Miller. 2008. "Bootstrap-based improvements for inference with clustered errors." The Review of Economics and Statistics 90(3):414-427.

Campbell, Donald T. and Julian C. Stanley. 1966. Experimental and Quasi-Experimental Designs for Fesearch. Chicago: Rand McNally.

Cantoni, Davide, Yuyu Chen, David Y. Yang, Noam Yuchtman and Y. Jane Zhang. 2017. "Curriculum and ideology." Journal of Political Economy 125(2):338-392.

Cavaillé, Charlotte and John Marshall. 2019. "Education and anti-immigration attitudes: Evidence from compulsory schooling reforms across Western Europe." American Political Science Review 113(1):254-263.

Chabé-Ferret, Sylvain. 2015. "Analysis of the bias of matching and difference-in-difference under alternative earnings and selection processes." Journal of Econometrics 185(1):110 123.

Chen, Hsiao-Lan Sharon and Hsuan-Yi Huang. 2017. "Advancing 21st century competencies in Taiwan." National Taiwan Normal University pp. 1-21. 
Citrin, Jack, Donald P. Green, Christopher Muste and Cara Wong. 1997. "Public opinion toward immigration reform: The role of economic motivations." Journal of Politics 59(3):858-881.

Corcuff, Stéphane. 2013. History textbooks, identity politics, and ethnic introspection in Taiwan: The June 1997 Knowing Taiwan textbooks controversy and the questions it raised on the various approaches to "Han" identity. In E. Vickers and A. Jones (eds.), History Education and National Identity in East Asia. Abingdon: Routledge, chapter 4, pp. 143-180.

Darden, Keith and Anna Grzymala-Busse. 2006. "The great divide: Literacy, nationalism, and the communist collapse.” World Politics 59(1):83-115.

Duflo, Esther. 2001. "Schooling and labor market consequences of school construction in Indonesia: Evidence from an unusual policy experiment." American Economic Review 91(4):795-813.

Feinstein, Yuval. 2016. "Pulling the trigger: how threats to the nation increase support for military action via the generation of hubris." Sociological Science 3:317-334.

Feinstein, Yuval and Bart Bonikowski. 2019. "Nationalist narratives and anti-Immigrant attitudes: exceptionalism and collective victimhood in contemporary Israel." Journal of Ethnic and Migration Studies pp. 1-21.

Friedman, Willa, Michael Kremer, Edward Miguel and Rebecca Thornton. 2016. "Education as liberation?" Economica 83(329):1-30.

Gerschewski, Johannes. 2013. "The three pillars of stability: legitimation, repression, and co-optation in autocratic regimes." Democratization 20(1):13-38.

Goldstein, Dana. 2020. “Two States. Eight Textbooks. Two American Stories.” https: //www.nytimes.com/interactive/2020/01/12/us/texas-vs-california-hist ory-textbooks.html. New York Times. (Accessed: 2021-10-25).

Greenfeld, Liah. 1992. Nationalism: Five Roads to Modernity. Cambridge, MA: Harvard University Press.

Grever, Maria and Tina Van der Vlies. 2017. "Why national narratives are perpetuated: A literature review on new insights from history textbook research." London Review of Education 15(2):286-301.

Hainmueller, Jens and Daniel J. Hopkins. 2014. "Public attitudes toward immigration." Annual Review of Political Science 17:225-249.

Hainmueller, Jens and Michael J. Hiscox. 2007. "Educated preferences: Explaining attitudes toward immigration in Europe." International Organization 61(2):399-442.

Hainmueller, Jens and Michael J. Hiscox. 2010. "Attitudes toward highly skilled and lowskilled immigration: Evidence from a survey experiment." American Political Science Review 104(1):61-84.

Hardwick, W. Susan, Rebecca Marcus and Marissa Isaak. 2010. "Education and national identity in a comparative context." National Identities 12(3):253-268. 
Henry, P. J. and Jaime L. Napier. 2017. "Education is related to greater ideological prejudice." Public Opinion Quarterly 81(4):930-942.

Hiers, Wesley, Thomas Soehl and Andreas Wimmer. 2017. "National trauma and the fear of foreigners: How past geopolitical threat heightens anti-immigration sentiment today." Social Forces 96(1):361-388.

Hsiau, A-chin. 2021. Politics and Cultural Nativism in 1970s Taiwan: Youth, Narrative, Nationalism. New York: Columbia University Press.

Huang, Min-Hsiung. 2019. "High school admission reforms, equality of educational opportunity, and academic performance in Taiwan." Harvard-Yenching Institute Working Paper Series .

Hur, Aram. 2020. "Citizen duty and the ethical power of communities: Mixed-method evidence from East Asia.” British Journal of Political Science 50(3):1047-1065.

Idris, Fazilah, Zaharah Hassan, Azizah Ya'acob, Saran Kaur Gill and Noor Aziah Mohd Awal. 2012. "The role of education in shaping youth's national identity." Procedia-Social and Behavioral Sciences 59:443-450.

Imai, Kosuke and Marc Ratkovic. 2014. "Covariate balancing propensity score." Journal of the Royal Statistical Society: Series B: Statistical Methodology pp. 243-263.

Keating, Michael. 1997. "Stateless nation-building: Quebec, Catalonia and Scotland in the changing state system." Nations and Nationalism 3(4):689-717.

Kohn, Hans and Craig Calhoun. 2017. The Idea of Nationalism: A Study in Its Origins and Background. Abingdon: Routledge.

Krastev, Ivan. 2017. After Europe. Philadelphia: University of Pennsylvania Press.

Kupchan, Charles. 1995. Nationalism and Nationalities in the New Europe. Ithaca, NY: Cornell University Press.

Kuzio, Taras. 2002. "The myth of the civic state: a critical survey of Hans Kohn's framework for understanding nationalism." Ethnic and Racial studies 25(1):20-39.

Lancee, Bram and Oriane Sarrasin. 2015. "Educated preferences or selection effects? A longitudinal analysis of the impact of educational attainment on attitudes towards immigrants." European Sociological Review 31(4):490-501.

Lechner, Michael. 2011. "The estimation of causal effects by difference-in-difference methods." Foundations and Trends in Econometrics 4(3):165-224.

Lerch, C. Julia, Garnett S. Russell and Francisco O. Ramirez. 2017. "Wither the nation-state? A comparative analysis of nationalism in textbooks." Social Forces 96(1):153-180.

Liu, Chuyu and Xiao Ma. 2018. "Popular threats and nationalistic propaganda: Political logic of China's patriotic campaign.” Security Studies 27(4):633-664.

Lui, Mei-Hui, Li-Ching Hung and Edward Vickers. 2013. Identity issues in Taiwan's history curriculum. In E. Vickers and A. Jones (eds.), History Education and National Identity in East Asia. Abingdon: Routledge, chapter 3, pp. 101-131. 
Ma, Yingyi. 2009. "Family socioeconomic status, parental involvement, and college major choices-gender, race/ethnic, and nativity patterns." Sociological Perspectives 52(2):211234.

Mayda, Anna Maria. 2006. "Who is against immigration? A cross-country investigation of individual attitudes toward immigrants." Review of Economics and Statistics 88(3):510_ 530 .

Morris, Paul, Naoko Shimazu and Edward Vickers. 2014. Imagining Japan in Post-war East Asia: Identity Politics, Schooling and Popular Culture. Routledge.

NCSS. 2010. National Curriculum Standards for Social Studies: A Framework for Teaching, Learning, and Assessment. Silver Spring, Md : National Council for the Social Studies.

Paglayan, Agustina S. 2021. "The non-democratic roots of mass education: Evidence from 200 years." American Political Science Review 115(1):179-198.

Pehrson, Samuel, Vivian L. Vignoles and Rupert Brown. 2009. "National identification and anti-immigrant prejudice: Individual and contextual effects of national definitions." Social Psychology Quarterly 72(1):24-38.

Rindermann, Heiner and Stephen J. Ceci. 2018. "Parents' education is more important than their wealth in shaping their children's intelligence: Results of 19 samples in seven countries at different developmental levels." Journal for the Education of the Gifted 41(4):298-326.

Rosenbaum, R. Paul and Donald B. Rubin. 1983. "The central role of the propensity score in observational studies for causal effects." Biometrika 70(1):41-55.

Rosenzweig, R. Leah and Yang-Yang Zhou. 2020. "Team and nation: Sports, nationalism, and attitudes toward refugees." Comparative Political Studies pp. 1-32.

Scheve, F. Kenneth and Matthew J. Slaughter. 2001. "Labor market competition and individual preferences over immigration policy." Review of Economics and Statistics 83(1):133145.

Scheve, Kenneth and Matthew J. Slaughter. 2006. Public opinion, international economic integration and the welfare state. In D. R. Cameron, G. Ranis, and A. Zinn (eds.), Globalization and Self-Determination. Abingdon: Routledge pp. 69-112.

Shayo, Moses. 2009. "A model of social identity with an application to political economy: Nation, class, and redistribution.” American Political Science Review 103(2):147-174.

Sides, John and Jack Citrin. 2007. "European opinion about immigration: The role of identities, interests and information." British Journal of Political Science 37(3):477-504.

Simonsen, Kristina Bakkaer and Bart Bonikowski. 2020. "Is civic nationalism necessarily inclusive? Conceptions of nationhood and anti-Muslim attitudes in Europe." European Journal of Political Research 59(1):114-136.

Smith, Anthony. 2005. Civic and ethnic nationalism. In P. Spencer and H. Wollman (eds.), Nations and Nationalism: A Reader. Edinburgh: Edinburgh University Press pp. 177-83. 
Sniderman, M. Paul, Louk Hagendoorn and Markus Prior. 2004. "Predisposing factors and situational triggers: Exclusionary reactions to immigrant minorities." American Political Science Review 98(1):35-49.

Sonnert, Gerhard. 2009. "Parents who influence their children to become scientists: Effects of gender and parental education." Social Studies of Science 39(6):927-941.

Stuart, A. Elizabeth, Gary King, Kosuke Imai and Daniel Ho. 2011. "MatchIt: nonparametric preprocessing for parametric causal inference.” Journal of Statistical Software 42(8):1-28.

Su, Ya-Chen. 1998. "Changing minds: How elementary social studies textbooks both reflect and change society." International Journal of Social Education 12(2):76-104.

Su, Ya-Chen. 2006. "Political ideology and Taiwanese school curricula." Asia Pacific Education Review 7(1):41-50.

Surridge, Paula. 2016. "Education and liberalism: pursuing the link." Oxford Review of Education 42(2):146-164.

Tamir, Yael. 2019. "Not so civic: is there a difference between ethnic and civic nationalism?" Annual Review of Political Science 22:419-434.

Tonkens, Evelien and Jan Willem Duyvendak. 2016. Introduction: The culturalization of citizenship. In J. W. Duyvendak, P. Geschiere, and E. Tonkens (eds.), The Culturalization of Citizenship. London: Springer pp. 1-20.

Van der Zwet, Arno. 2015. "Operationalising national identity: the cases of the Scottish National Party and Frisian National Party." Nations and Nationalism 21(1):62-82.

Van Heelsum, Anja and Maarten Koomen. 2016. "Ascription and identity. Differences between first-and second-generation Moroccans in the way ascription influences religious, national and ethnic group identification." Journal of Ethnic and Migration Studies 42(2):277-291.

Wang, Amy. 2017. "For decades, no one spoke of Taiwan's hidden massacre. A new generation is breaking the silence." https://www. washingtonpost.com/news/worldv iews/wp/2017/02/28/for-decades-no-one-spoke-of-taiwans-hidden-massac re-a-new-generation-is-breaking-the-silence/. Washington Post. (Accessed: 2021-11-02).

Wang, Fu-chang. 2005. Why bother about school textbooks?: An analysis of the origin of the disputes over Renshi Taiwan textbooks in 1997. In J. Makeham and A. Hsiau (eds.), Cultural, Ethnic, and Political Nationalism in Contemporary Taiwan. New York: Springer pp. 55-99.

Weber, Eugen. 1976. Peasants into Frenchmen: The Modernization of Rural France, 18701914. Stanford: Stanford University Press.

Wimmer, Andreas. 2013. Ethnic Boundary Making: Institutions, Power, Networks. New York: Oxford University Press.

Yinan, He. 2014. "Identity politics and foreign policy: Taiwan's relations with China and Japan, 1895-2012.” Politcal Science Quarterly 129:469-500.

Zeldow, Bret and Laura A. Hatfield. 2019. "Confounding and Regression Adjustment in Difference-in-Differences.” arXiv preprint arXiv:1911.12185 . 


\section{Supplementary Online Appendices The Impact of Educational Content on Anti-Immigrant Attitudes: Evidence from Taiwan}

\section{Contents}

A Changes in the Renshi Taiwan Textbooks 35

B Data Description 36

B.1 Source of Data . . . . . . . . . . . . . . 36

B.2 Sample Distribution by County/City . . . . . . . . . . . . 37

B.3 Coding Educational Path . . . . . . . . . . . . . . . . 37

B.4 Coding Attitudes towards Immigrants . . . . . . . . . . . . . . . 38

B.5 Birth Year, School Cohort, and Corresponding Age in 1997 . . . . . . . . 38

C Summary Statistics

C.1 Summary Statistics for Overall Sample . . . . . . . . . . . . . . . . . . . 39

C.2 Summary Statistics for Pre- and Post-Renshi Taiwan . . . . . . . . . . . 40

D Descriptions and Results on the Matched Sample 41

D.1 Balance Statistics for Matched Sample . . . . . . . . . . . . . . . . . 41

D.2 Results from the Matched Sample with Pre-Treatment Covariates . . . . . . 42

E Main Model Results $\quad 44$

E.1 Pre- and Post-Treatment Covariates . . . . . . . . . . . . . . . . 44

F Robustness Checks $\quad \mathbf{4 5}$

F.1 Different Comparison Groups . . . . . . . . . . . . . . . . 45

F.2 Short- vs. Long-term Effect . . . . . . . . . . . . . . . . . . . . . . 46

F.3 Analysis with Different Clustered Robust Standard Errors . . . . . . . . . . 47 


\section{A Changes in the Renshi Taiwan Textbooks}

This section discusses further evidence related to the changes in the Renshi Taiwan textbooks based on actual (used) textbooks I obtained through Taiwanese online stores. I purchased 5-volume history textbooks published in 1996 (8th edition, the Republic of China calendar year of 85: 中民八十五年八月改編本八版) as well as the Renshi Taiwan history and society textbooks published in 2000 (2nd edition, the Republic of China calendar year of 89: 中民八十九年八月正式本再版改二刷). Figure A.1 and Figure A.2 show original excerpts from the Renshi Taiwan textbooks, as discussed in the main text.

Figure A.1: Learning Objectives presented in the Renshi Taiwan Textbooks

(a) Society textbook

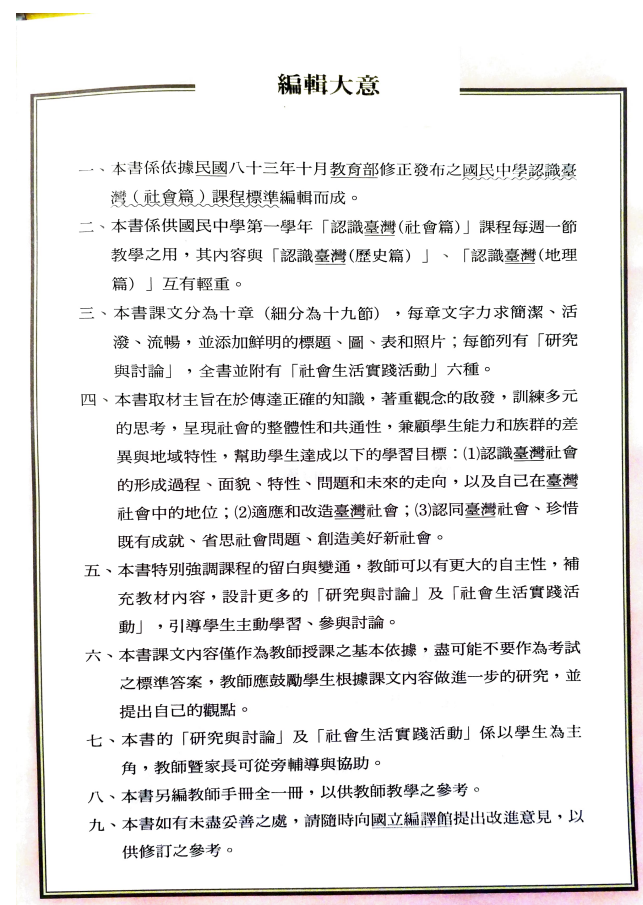

(b) History textbook

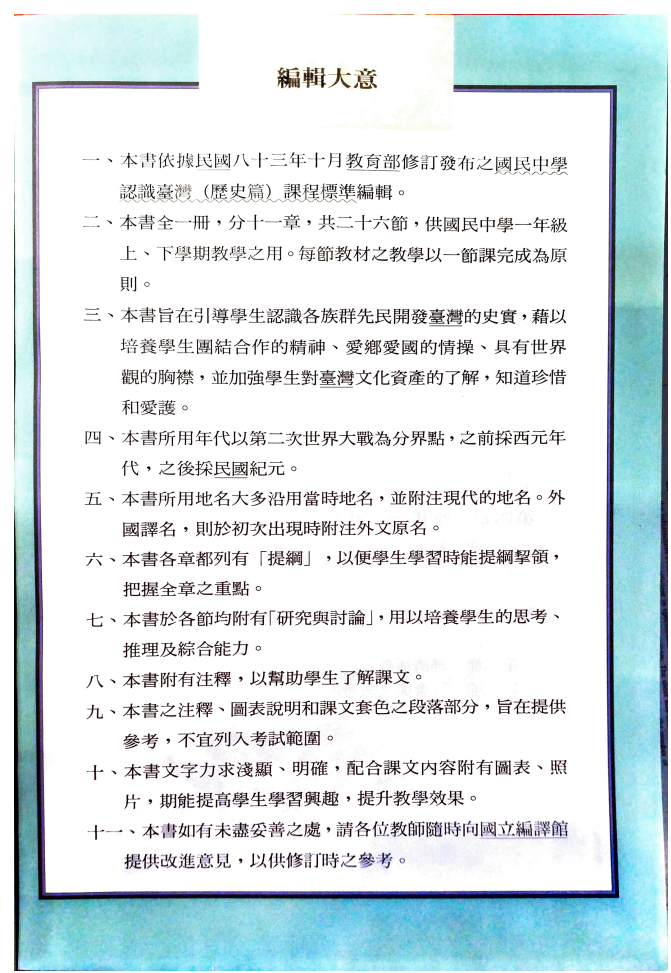

Figure A.1 and Figure A.2 show excerpts from the Renshi Taiwan textbooks. As discussed in the main text, Figure A.1 (a) under the fourth point(四) presents the purpose of the Society textbook: identify with Taiwanese society, cherish existing achievements, reflect on social issues, and create a beautiful new society. Similarly, the goal of the History textbook, as shown in Figure A.1 (b) under the third point(三), is "to guide students to understand the historical facts of the development of Taiwan by the ancestors of various ethnic groups...understanding of Taiwan's cultural assets, knowing to cherish and love them." 
Figure A.2: Chronology of History presented in the Renshi Taiwan Textbooks

(a) Old textbook

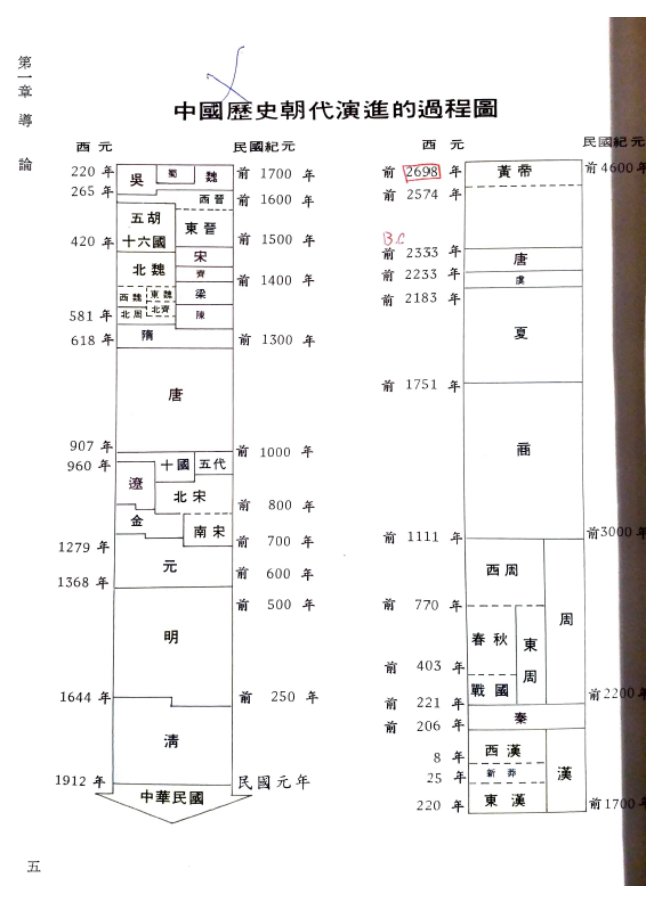

(b) Renshi Taiwan textbook

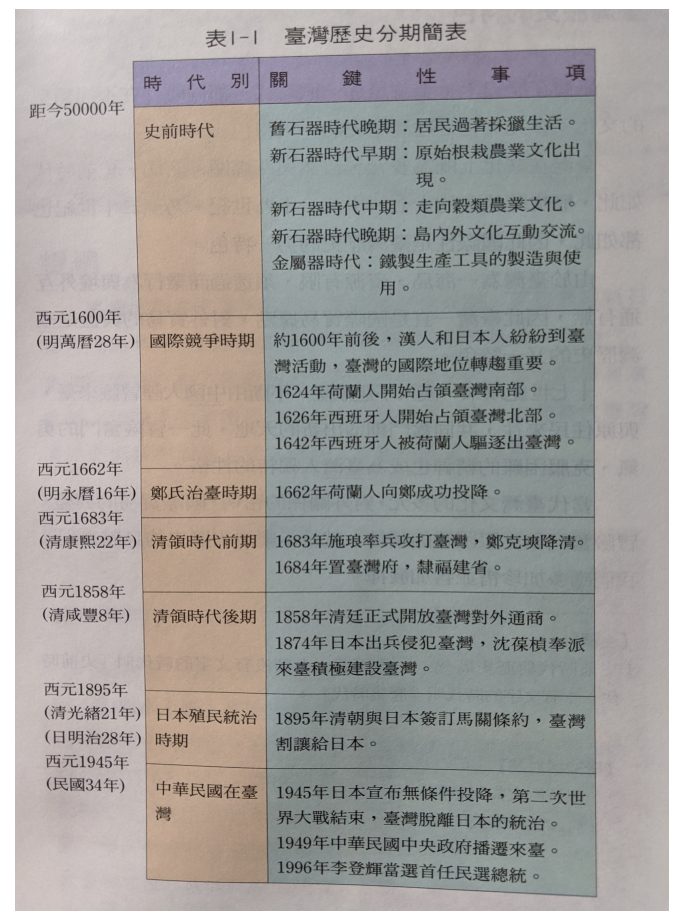

\section{B Data Description}

\section{B.1 Source of Data}

Data analyzed in this research were collected in the following round/phase, year, and topic of the research project "Taiwan Social Change Survey": Survey 2005 (Phase 5, Wave 1: Work Orientation), survey 2008 (Round 5, Year 4: Globalization and Culture), survey 2010 (Round 6, Year 1: Globalization), survey 2013 (Round 6, Year 4: National Identity), and survey 2015 (Round 7, Year 1: Globalization). The project was conducted by the Institute of Sociology, Academia Sinica (data gathered before the first Year of the third Round were conducted by the Institute of Ethnology, Academia Sinica), and sponsored by the Ministry of Science and Technology (formerly known as National Science Council), Republic of China. The data can be downloaded at https://www2.ios.sinica.edu.tw/sc/en/scDownload3.php 


\section{B.2 Sample Distribution by County/City}

Figure B.3: Distribution of Survey Respondents. Dashed line represents the first birth cohort (i.e., born between September 1984 and August 1985) impacted by the introduction of the Renshi Taiwan textbooks in 1997. Lienchiang, Kinmen, and Penghu County are very small islands; out of original 5 waves of TSCS data with about 6,000 observations, only 35 observations are from these two counties.

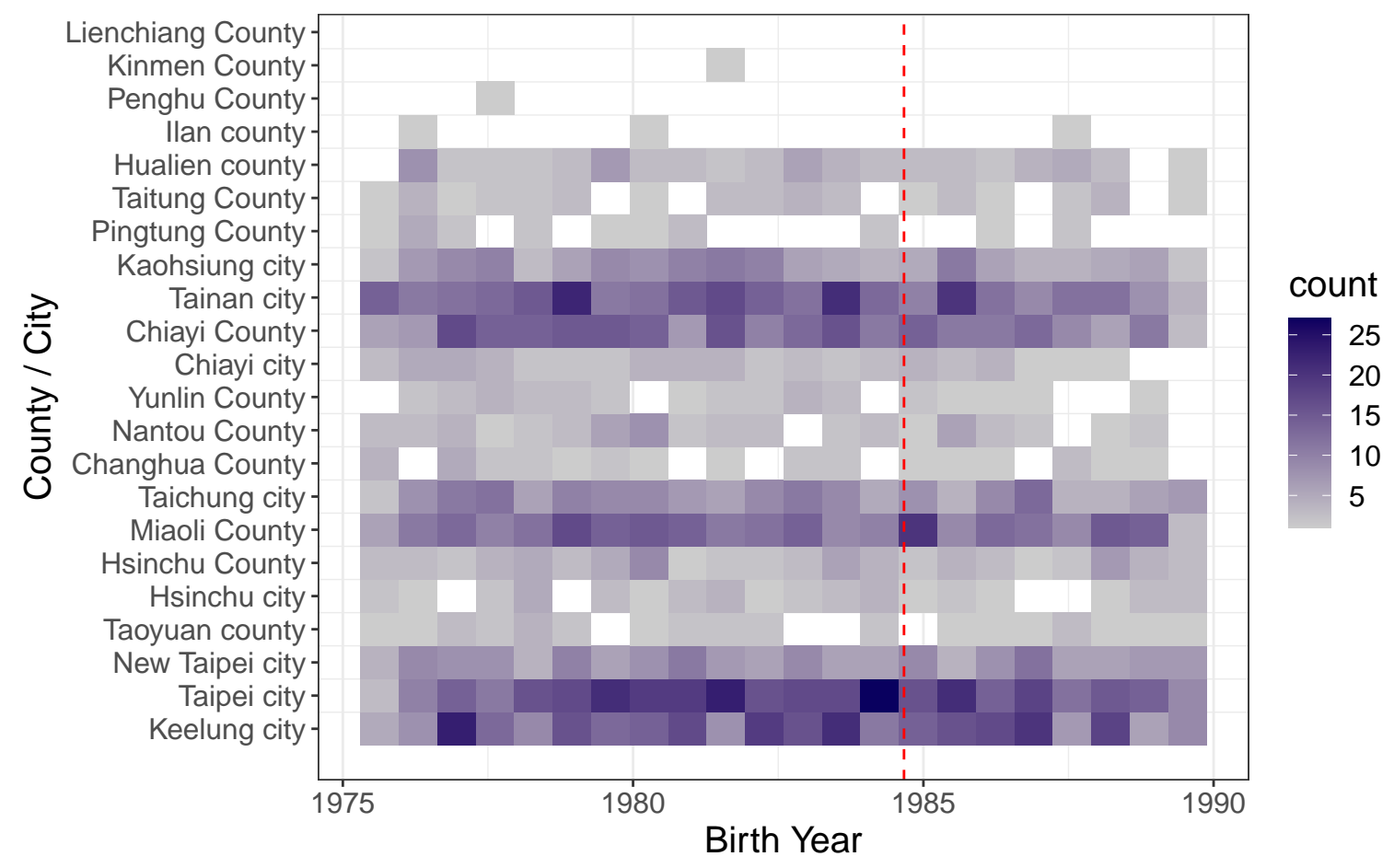

Due to the sampling method of TSCS based on the levels of regions, respondents are distributed in proportion to the size of each region as shown in Figure B.3. To account for the potential effect of geographic region, I include region fixed effects in all models. The variable that indicates the location of birth is used to approximate respondents' region of education. As discussed in the main text (footnote 7), this is a reasonable proxy because many respondents said that they lived the longest in the same region in which they were born.

\section{B.3 Coding Educational Path}

The TSCS survey asks the highest education level achieved with detailed answer categories. Instead of a crude classification of elementary school, middle school, high school, college/university, and graduate level, it provides a list of specific educational institutions that are either academic or vocational schools. For example, the categories of response for high school graduates include "Senior high school (General class)", "Senior high school (Vocational class)", and "Vocational Senior high school". Respondents are coded as a taken academic path when their highest level of education is clearly associated with an academic-path, as 
opposed to a vocational-path, institution. Specifically, the academic path institutions include: High school (general subjects) (高中普通科), Three-year junior college (after high school of general subjects) (三專), College/University (大學), and Graduate Degree (碩士, 博 士). Vocational path includes Vocational junior high school (初職), High school (vocational subjects) (高中職業科), Vocational high school (高職), Cadet school (士官學校), Five-year junior college (after junior high) (五專), Two-year junior college (after vocational high school) (二專), Military/police junior college (one-year; 軍警專修班) or college (two-year or more; 軍警專科班, or 軍警官學校), Open junior college (空中行專), and Technological college, science and technological college (二技、四技).

\section{B.4 Coding Attitudes towards Immigrants}

In 2008, 2010, and 2015 waves, the question used "foreign workers" or "foreign laborers" instead of "immigrants" in its wording. This question reflects the respondents' opposition to immigrants - a respondent who prefers a reduction in the number of foreign workers or laborers is considered to have negative feelings about immigrants.

\section{B.5 Birth Year, School Cohort, and Corresponding Age in 1997}

Table B.1: Textbook Introduction depending on Birth Year-Month, School Year, and Age in 1997 Under Analysis

\begin{tabular}{lccc}
\hline \hline Birth Year - Month & $\begin{array}{c}\text { Year entered into the junior } \\
\text { high school (School cohort) }\end{array}$ & Age in 1997 & Old vs. New textbooks used \\
\hline From 1975-Sep to 1976-Aug & 1988 & $21-22$ & Old \\
From 1976-Sep to 1977-Aug & 1989 & $20-21$ & Old \\
From 1977-Sep to 1978-Aug & 1990 & $19-20$ & Old \\
From 1978-Sep to 1979-Aug & 1991 & $18-19$ & Old \\
From 1979-Sep to 1980-Aug & 1992 & $17-18$ & Old \\
From 1980-Sep to 1981-Aug & 1993 & $16-17$ & Old \\
From 1981-Sep to 1982-Aug & 1994 & $15-16$ & Old \\
From 1982-Sep to 1983-Aug & 1995 & $14-15$ & Old \\
From 1983-Sep to 1984-Aug & 1996 & $13-14$ & Old \\
From 1984-Sep to 1985-Aug & 1997 & $12-13$ & New (Renshi Taiwan) \\
From 1985-Sep to 1986-Aug & 1998 & $11-12$ & New (Renshi Taiwan) \\
From 1986-Sep to 1987-Aug & 1999 & $10-11$ & New (Renshi Taiwan) \\
From 1987-Sep to 1988-Aug & 2000 & $9-10$ & New (Renshi Taiwan) \\
From 1988-Sep to 1989-Aug & 2001 & $8-9$ & New (Renshi Taiwan) \\
\hline \hline
\end{tabular}

This paper uses the birth year and month, school cohort, and age in 1997 (when the Renshi Taiwan textbooks were introduced) interchangeably. To minimize confusion coming from different terms, Table B.1 is prepared to help readers to understand their relationship. The cells with gray background indicate those who received the new textbooks in terms of their birth year-month, school year, and age in 1997. 


\section{Summary Statistics}

\section{C.1 Summary Statistics for Overall Sample}

Table C. 2 reports summary statistics of the main variables for both the entire sample in the dataset and sample used in Table 2 in the main text.

Table C.2: Summary Statistics for Overall Sample

\begin{tabular}{llllllll}
\hline \hline Variable & $\mathrm{N}$ & Mean & St. Dev. & Min & $\operatorname{Pctl}(25)$ & $\operatorname{Pctl}(75)$ & Max \\
\hline
\end{tabular}

Entire sample in the dataset

\begin{tabular}{lllllllc} 
Preferred Num. of Immigrants & 2,381 & 2.488 & 1.044 & 1 & 2 & 3 & 5 \\
Educational path (academic = 1) & 2,293 & 0.417 & 0.493 & 0 & 0 & 1 & 1 \\
New (post reform = 1) & 2,381 & 0.319 & 0.466 & 0 & 0 & 1 & 1 \\
Female (female = 1) & 2,381 & 0.481 & 0.500 & 0 & 0 & 1 & 1 \\
Married (married = 1) & 2,380 & 0.300 & 0.458 & 0 & 0 & 1 & 1 \\
Employed (employed = 1) & 2,375 & 0.791 & 0.407 & 0 & 1 & 1 & 1 \\
Self-evaluated social class & 1,949 & 5.219 & 1.584 & 1 & 5 & 6 & 1 \\
Higher education (high = 1) & 2,381 & 0.696 & 0.460 & 0 & 0 & 1 & 1 \\
Bachelor's degree (BA = 1) & 2,381 & 0.543 & 0.498 & 0 & 0 & 1 & 1 \\
Parent's path (academic = 1) & 1,229 & 0.461 & 0.499 & 0 & 0 & 1 & 1 \\
\hline
\end{tabular}

Sample used in Table 3 Model (2)

\begin{tabular}{lccccccc} 
Preferred Num. of Immigrants & 987 & 2.630 & 1.025 & 1 & 2 & 3 & 5 \\
Educational Path (academic $=1)$ & 987 & 0.549 & 0.498 & 0 & 0 & 1 & 1 \\
New (post reform = 1) & 987 & 0.433 & 0.496 & 0 & 0 & 1 & 1 \\
Female (female = 1) & 987 & 0.490 & 0.500 & 0 & 0 & 1 & 1 \\
Married (married = 1) & 987 & 0.244 & 0.430 & 0 & 0 & 0 & 1 \\
Employed (employed = 1) & 987 & 0.769 & 0.422 & 0 & 1 & 1 & 1 \\
Self-evaluated social class & 987 & 5.278 & 1.496 & 1 & 5 & 6 & 10 \\
Higher education (high = 1) & 987 & 0.853 & 0.354 & 0 & 1 & 1 & 1 \\
Parent's path (academic = 1) & 987 & 0.455 & 0.498 & 0 & 0 & 1 & 1 \\
\hline
\end{tabular}




\section{C.2 Summary Statistics for Pre- and Post-Renshi Taiwan}

Table C. 3 reports summary statistics of the main variables for school cohorts who received the old textbooks and those who received the Renshi Taiwan textbooks.

Table C.3: Summary Statistics by School Cohort

\begin{tabular}{llllllll}
\hline \hline Variable & $\mathrm{N}$ & Mean & St. Dev. & Min & $\operatorname{Pctl}(25)$ & $\operatorname{Pctl}(75)$ & Max \\
\hline
\end{tabular}

Post-Renshi Taiwan cohort

(Ages 8-9 to 12-13 in 1997)

\begin{tabular}{lccccccc} 
Preferred Num. of Immigrants & 759 & 2.564 & 1.030 & 1 & 2 & 3 & 5 \\
Educational Path (academic = 1) & 743 & 0.505 & 0.500 & 0 & 0 & 1 & 1 \\
Female (female = 1) & 759 & 0.494 & 0.500 & 0 & 0 & 1 & 1 \\
Married (married = 1) & 759 & 0.108 & 0.311 & 0 & 0 & 0 & 1 \\
Employed (employed = 1) & 758 & 0.650 & 0.477 & 0 & 0 & 1 & 1 \\
Self-evaluated social class & 675 & 5.041 & 1.516 & 1 & 4 & 6 & 10 \\
Higher education (high = 1) & 759 & 0.783 & 0.413 & 0 & 1 & 1 & 1 \\
Bachelor's degree (BA = 1) & 759 & 0.710 & 0.454 & 0 & 0 & 1 & 1 \\
Parent's path (academic = 1) & 493 & 0.448 & 0.498 & 0 & 0 & 1 & 1 \\
\hline
\end{tabular}

\section{Pre-Renshi Taiwan cohort}

(Ages 13-14 to 21-22 in 1997)

\begin{tabular}{lccccccc} 
Preferred Num. of Immigrants & 1,622 & 2.453 & 1.048 & 1 & 2 & 3 & 5 \\
Educational Path (academic = 1) & 1,550 & 0.375 & 0.484 & 0 & 0 & 1 & 1 \\
Female (female = 1) & 1,622 & 0.475 & 0.500 & 0 & 0 & 1 & 1 \\
Married (married = 1) & 1,621 & 0.389 & 0.488 & 0 & 0 & 1 & 1 \\
Employed (employed = 1) & 1,617 & 0.857 & 0.351 & 0 & 1 & 1 & 1 \\
Self-evaluated social class & 1,274 & 5.312 & 1.611 & 1 & 5 & 6 & 10 \\
Higher education (high = 1) & 1,622 & 0.656 & 0.475 & 0 & 0 & 1 & 1 \\
Bachelor's degree (BA = 1) & 1,622 & 0.465 & 0.499 & 0 & 0 & 1 & 1 \\
Parent's path (academic = 1) & 736 & 0.469 & 0.499 & 0 & 0 & 1 & 1 \\
\hline
\end{tabular}




\section{Descriptions and Results on the Matched Sample}

\section{D.1 Balance Statistics for Matched Sample}

Matching is conducted using MatchIt package in R. I used the nearest neighbor option that matches a given treated subject to an untreated subject whose propensity score is the closest. Also, the matching is calipered at 0.1 standard deviation of propensity scores. The education level variable is not included in the matching model due to collinearity to the treatment variable. For matching, I only use variables that show statistically significant mean differences between the vocational and academic groups in the original data. For matching on pre-treatment covariates, I used female, parent's path, location of birth, cohort year, and survey year.

Figure D.4: Balance plot for matched data

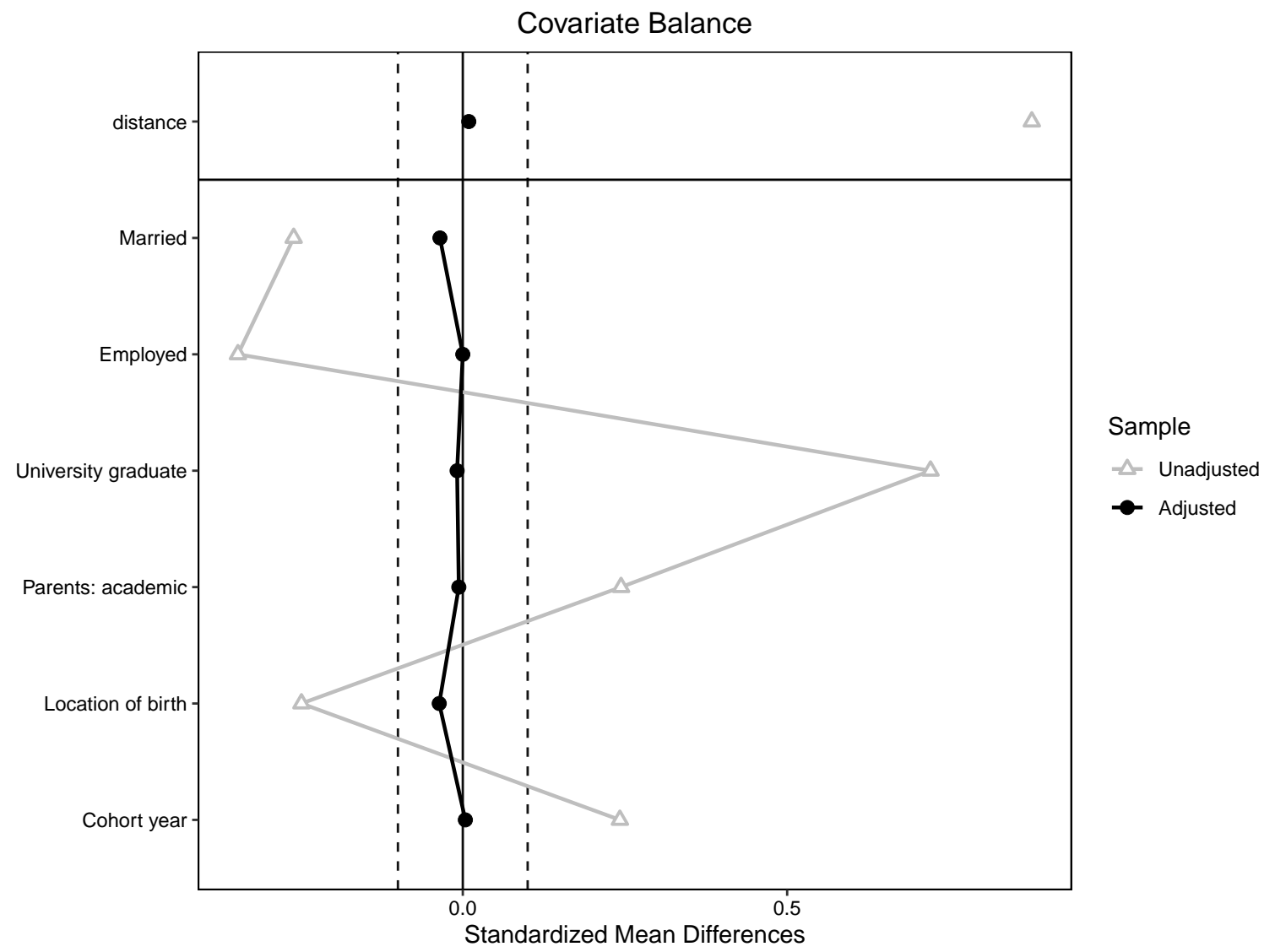

Figure D.4 shows the result in mean differences before (unadjusted) and after (adjusted) matching with a threshold for balance statistics of 0.1 . For standardized mean differences, a threshold of 0.1 is recommended in assessing imbalance that would lead to biased effect estimation. As the result shows, previously imbalanced variables are fairly balanced after the matching process. This is also clear in Table D.4. Before the matching, the two groups showed 
differences in most of the variables. After the matching, the imbalances are significantly reduced - the main variables for the vocational and academic groups are very similar in their means.

Table D.4: Group Means for original and matched data

\begin{tabular}{|c|c|c|c|c|c|c|}
\hline & \multicolumn{3}{|c|}{ Before matching $(\mathrm{N}=987)$} & \multicolumn{3}{|c|}{ After matching $(\mathrm{N}=664)$} \\
\hline & $\begin{array}{c}\text { Vocational } \\
\text { (Comparison) }\end{array}$ & $\begin{array}{l}\text { Academic } \\
\text { (Treatment) }\end{array}$ & $\mathrm{P}$-value & $\begin{array}{c}\text { Vocational } \\
\text { (Comparison) }\end{array}$ & $\begin{array}{l}\text { Academic } \\
\text { (Treatment) }\end{array}$ & P-value \\
\hline Female (female $=1$ ) & 0.4809 & 0.4981 & 0.5899 & 0.5196 & 0.4834 & 0.3517 \\
\hline Married (married = 1) & 0.3056 & 0.1937 & $<0.01$ & 0.2598 & 0.2447 & 0.6551 \\
\hline Employed (employed = 1) & 0.8472 & 0.7048 & $<0.01$ & 0.8308 & 0.83081 & 1.0000 \\
\hline Self-evaluated social class & 5.2180 & 5.3266 & 0.2611 & 5.2266 & 5.3595 & 0.2606 \\
\hline Higher education $($ high $=1)$ & 0.7169 & 0.9649 & $<0.01$ & 0.9456 & 0.9426 & 0.8659 \\
\hline Parent's path $($ academic $=1)$ & 0.3888 & 0.5092 & $<0.01$ & 0.3988 & 0.3958 & 0.9368 \\
\hline Location of birth & 9.3753 & 8.0092 & $<0.01$ & 9.2357 & 9.0363 & 0.6398 \\
\hline Cohort year & 1994.838 & 1995.768 & $<0.01$ & 1995.193 & 1995.208 & 0.9591 \\
\hline Survey year & 2011.036 & 2010.978 & 0.7361 & 2011.082 & 2011.308 & 0.2875 \\
\hline
\end{tabular}

\section{D.2 Results from the Matched Sample with Pre-Treatment Covariates}

Researchers often use matching on pre-period covariates to correct for potential confounding bias. As Table D.5 shows, the main results remains similar when matching uses pre-treatment covariates or when it uses both pre- and post-covariates. 
Table D.5: Results from the Matched Sample with Pre- and Post-treatment Covariates

\begin{tabular}{|c|c|c|}
\hline & \multicolumn{2}{|c|}{ DV: Preference for increased number of Immigrants } \\
\hline & $(1)$ & $(2)$ \\
\hline & $\begin{array}{c}\text { Matched with Pre-Treatment } \\
\text { Covariates }\end{array}$ & $\begin{array}{l}\text { Matched with Pre- and } \\
\text { Post-Treatment Covariates }\end{array}$ \\
\hline \multirow{2}{*}{ Academic $\times$ New } & $-0.185^{* * *}$ & $-0.196^{* *}$ \\
\hline & $(0.066)$ & $(0.095)$ \\
\hline \multirow{2}{*}{ Academic } & 0.544 & 0.480 \\
\hline & $(0.342)$ & $(0.379)$ \\
\hline \multirow[t]{2}{*}{ New } & 0.070 & 0.094 \\
\hline & $(0.122)$ & $(0.163)$ \\
\hline \multirow{2}{*}{ Gender $($ Female $=1)$} & $-0.167^{* *}$ & -0.108 \\
\hline & $(0.066)$ & $(0.073)$ \\
\hline \multirow{2}{*}{ Parents' Path (Academic = 1) } & 0.098 & 0.137 \\
\hline & $(0.132)$ & $(0.155)$ \\
\hline \multirow[t]{2}{*}{ Parents' Path $\times$ New } & -0.185 & -0.167 \\
\hline & $(0.170)$ & $(0.190)$ \\
\hline \multirow[t]{2}{*}{ Marital (Married = 1) } & $-0.205^{* * *}$ & -0.120 \\
\hline & $(0.073)$ & $(0.085)$ \\
\hline \multirow[t]{2}{*}{ Employment (Employed = 1) } & -0.170 & -0.158 \\
\hline & $(0.111)$ & $(0.105)$ \\
\hline \multirow[t]{2}{*}{ Subjective Social Class } & 0.013 & 0.019 \\
\hline & $(0.028)$ & $(0.028)$ \\
\hline \multirow[t]{2}{*}{ High Education (College or higher $=1$ ) } & 0.565 & 0.450 \\
\hline & $(0.450)$ & $(0.464)$ \\
\hline \multirow[t]{2}{*}{ Constant } & $2.383^{* * *}$ & $2.322^{* * *}$ \\
\hline & $(0.596)$ & $(0.617)$ \\
\hline Province FE & $\checkmark$ & $\checkmark$ \\
\hline Cohort FE & $\checkmark$ & $\checkmark$ \\
\hline Survey Year FE & $\checkmark$ & $\checkmark$ \\
\hline Education Level FE & $\checkmark$ & $\checkmark$ \\
\hline Observations & 798 & 662 \\
\hline $\mathrm{R}$-squared & 0.162 & 0.176 \\
\hline
\end{tabular}

Note: All models are estimated using ordinary least squares (OLS) with pre-treatment and post-treatment individual-level controls. Robust standard errors clustered by school cohorts $\times$ educational path are in parentheses. $* p<0.1, * * p<0.05, * * * p<0.01$ 


\section{E Main Model Results}

\section{E.1 Pre- and Post-Treatment Covariates}

Table E.6: Inclusion of Individual Controls

\begin{tabular}{|c|c|c|c|c|}
\hline & \multicolumn{4}{|c|}{ DV: Preference for increased number of Immigrants } \\
\hline & \multicolumn{2}{|c|}{ Pre-Treatment Covariates } & \multicolumn{2}{|c|}{ Pre- and Post-Treatment Covariates } \\
\hline & Original & Matched & Original & Matched \\
\hline \multirow[t]{2}{*}{ Academic $\times$ New } & $-0.133^{* * *}$ & $-0.204^{* *}$ & $-0.228^{* * *}$ & $-0.196^{* *}$ \\
\hline & $(0.061)$ & $(0.080)$ & $(0.064)$ & $(0.095)$ \\
\hline \multirow[t]{2}{*}{ Academic } & 0.337 & $0.275^{* * *}$ & $0.553^{*}$ & 0.480 \\
\hline & $(0.042)$ & $(0.069)$ & $(0.322)$ & $(0.379)$ \\
\hline \multirow[t]{2}{*}{ New } & $0.134^{* * *}$ & 0.219 & $0.122^{* *}$ & 0.094 \\
\hline & $(0.094)$ & $(0.146)$ & $(0.100)$ & $(0.163)$ \\
\hline \multirow[t]{2}{*}{ Gender $($ Female $=1)$} & $-0.084^{* * *}$ & -0.103 & $-0.144^{* * *}$ & -0.108 \\
\hline & $(0.040)$ & $(0.073)$ & $(0.049)$ & $(0.073)$ \\
\hline \multirow[t]{2}{*}{ Parents' Path $($ Academic $=1)$} & 0.080 & 0.136 & 0.129 & 0.137 \\
\hline & $(0.094)$ & $(0.154)$ & $(0.113)$ & $(0.156)$ \\
\hline \multirow[t]{2}{*}{ Parents' Path $\times$ New } & -0.105 & -0.173 & -0.208 & -0.167 \\
\hline & $(0.138)$ & $(0.188)$ & $(0.135)$ & $(0.190)$ \\
\hline \multirow[t]{2}{*}{ Marital (Married = 1) } & & & -0.100 & -0.120 \\
\hline & & & $(0.077)$ & $(0.085)$ \\
\hline \multirow[t]{2}{*}{ Employment (Employed = 1) } & & & $-0.155^{*}$ & -0.157 \\
\hline & & & $(0.093)$ & $(0.105)$ \\
\hline \multirow[t]{2}{*}{ Subjective Social Class } & & & 0.017 & 0.019 \\
\hline & & & $(0.025)$ & $(0.028)$ \\
\hline \multirow[t]{2}{*}{ High Education $($ College or higher $=1)$} & & & 0.490 & 0.450 \\
\hline & & & $(0.415)$ & $(0.464)$ \\
\hline \multirow[t]{2}{*}{ Constant } & $2.591^{* * *}$ & $2.626^{* * *}$ & $2.494^{* * *}$ & $2.322^{* * *}$ \\
\hline & $(0.285)$ & $(0.296)$ & $(0.596)$ & $(0.617)$ \\
\hline Province FE & $\checkmark$ & $\checkmark$ & $\checkmark$ & $\checkmark$ \\
\hline Cohort FE & $\checkmark$ & $\checkmark$ & $\checkmark$ & $\checkmark$ \\
\hline Survey Year FE & $\checkmark$ & $\checkmark$ & $\checkmark$ & $\checkmark$ \\
\hline Education Level FE & & & $\checkmark$ & $\checkmark$ \\
\hline Observations & 1219 & 662 & 987 & 662 \\
\hline $\mathrm{R}$-squared & 0.105 & 0.159 & 0.171 & 0.176 \\
\hline
\end{tabular}

Note: All models are estimated using ordinary least squares (OLS) with pre-treatment and post-treatment individual-level controls. Robust standard errors clustered by school cohorts $\times$ educational path are shown in parentheses. $* p<0.1, * * p<0.05, * * * p<0.01$

?? shows that having studied the new textbooks lead to stronger Taiwanese national identity. Respondents who studied the new textbooks feel significantly close to Taiwan $(p \leq 0.05)$. They also emphasize the importance of having born in Taiwan when identifying a true Taiwanese. The negative coefficients of the national identity based on the native-born status, although they are not statistically significant, provide evidence that the new textbooks promote an exclusive national identification. 


\section{F Robustness Checks}

\section{F.1 Different Comparison Groups}

To see whether the results in the main text are driven by the choice of the range of a comparison group, I redefine the comparison cohort using a 4-year window younger and older than the main comparison cohort. The new younger comparison cohorts are those who were aged from 13-14 to 17-18 in 1997, which includes the respondents from the cohorts just above those who first received the Renshi Taiwan textbooks to the cohorts who were in the age of graduating from senior high school. This means that the respondents in this range are younger than the main comparison group with a fresh memory of textbooks they learned in junior high schools. Also, respondents in this range would have less diverse life experiences, due to the younger age, which may dampen the textbook effect than those in the main comparison group.

I also check whether the inclusion of young adults affects the main results by analyzing with another new comparison cohorts who are 4 years older than the main comparison group, i.e., those who were aged 13-14 to 25-26 in 1997. The below table presents that the estimates of the educational content effect on anti-immigrant attitudes are robust to different comparison groups. In both comparison groups, the estimate on the interaction term remains negative and statistically significant.

Table F.7: The Effect of the New Textbooks by Different Comparison Groups

\begin{tabular}{lcc}
\hline \hline & \multicolumn{2}{c}{ DV: Preference for increased number of Immigrants } \\
\cline { 2 - 3 } & $(1)$ & $(2)$ \\
& Aged from $13-14$ to $17-18$ & Aged from 13-14 to 25-26 \\
\hline \hline Academic $\times$ New & $-0.209^{* * *}$ & $-0.255^{* * *}$ \\
Academic & $(0.074)$ & $(0.061)$ \\
& 0.094 & $0.518^{*}$ \\
New & $(0.385)$ & $(0.277)$ \\
& $0.314^{* * *}$ & $0.197^{* *}$ \\
Constant & $(0.089)$ & $(0.096)$ \\
& $2.704^{* * *}$ & $2.426^{* * *}$ \\
Observations & $(0.690)$ & $(0.535)$ \\
R-squared & 777 & 1129 \\
\hline \hline
\end{tabular}

Note: All models are estimated using ordinary least squares (OLS). Variables not shown include education level, cohort year, region of birth, and survey year fixed effects along with individual covariates such as gender, employment status, marital status, subjective social class, and high education (college graduate). Robust standard errors clustered by school cohorts $\times$ educational path are shown in parentheses. $* p<0.1, * * p<0.05, * * * p<0.01$ 


\section{F.2 Short- vs. Long-term Effect}

Since there is a significant time gap between the introduction of the Renshi Taiwan textbook series and the survey years, the effect of textbook content may have dissipated over time in the later survey years. To account for this issue, I explore this issue by examining the short-term and long-term samples separately. For the short-term sample, I include the survey year of 2005, 2008, and 2010. The cohort who firstly received the new textbooks (i.e., 1997 cohort) are aged 25-26 and those who lastly studied the new textbooks (i.e., 2001 cohort) are aged 21-22 in 2010 - the effect of education may persist until roughly 20-25 years old because it is likely that individuals change their attitudes depending on their life experience after education. For the long-term effect, I include survey years of 2013 and 2015. In 2015, the youngest and oldest cohort who studied the new textbooks are aged between 26-27 to 30-31.

As Table F.8 shows, I find that the Renshi Taiwan textbooks lower the level of support for increasing the number of immigrants when respondents are still relatively young by the time when the survey was conducted. The effect of educational content is weaker in the long run considering that the coefficient of long-term results is smaller than that of short-term results and is not statistically significant at the $5 \%$ level.

Table F.8: The Effect of the New Textbooks by Short-term and Long-term Sample

\begin{tabular}{lcc}
\hline \hline & \multicolumn{2}{c}{ DV: Preference for increased number of Immigrants } \\
\cline { 2 - 3 } & $(1)$ & $(2)$ \\
& Short-term sample & Long-term sample \\
\hline \hline Academic $\times$ New & $-0.255^{* *}$ & $-0.232^{*}$ \\
Academic & $(0.116)$ & $(0.130)$ \\
& -0.066 & 0.506 \\
New & $(0.163)$ & $(0.451)$ \\
& $0.328^{* *}$ & -0.055 \\
Constant & $(0.157)$ & $(0.191)$ \\
& $2.991^{* * *}$ & $2.238^{* * *}$ \\
& $(0.606)$ & $(0.690)$ \\
Observations & 572 & 415 \\
R-squared & 0.239 & 0.197 \\
\hline \hline
\end{tabular}

Note: Short-term sample includes the survey year of 2005, 2008, and 2010. Long-term sample includes the survey years of 2013 and 2015. All models are estimated using ordinary least squares (OLS). Variables not shown include education level, cohort year, region of birth, and survey year fixed effects along with individual covariates such as gender, employment status, marital status, subjective social class, and high education (college graduate). Robust standard errors clustered by school cohorts $\times$ educational path are shown in parentheses. $* p<0.1, * * p<0.05, * * * p<0.01$ 


\section{F.3 Analysis with Different Clustered Robust Standard Errors}

To assure that the main results are not driven by inappropriate use of clustered standard errors, I re-estimate the coefficients using different clustered robust standard errors. First, I use the method of bootstrapping as an alternative way to obtain clustered robust standard errors. Specifically, I use ClusterBootstrap package in $\mathrm{R}$, which provides various types of confidence intervals based on a bootstrap sample. I report bias-corrected and accelerated interval (BCs), instead of parametric or percentile interval, because it improves a correction for asymmetry among the bootstrap estimates and standard errors. ${ }^{9}$ The numbers of bootstrap samples are set to 1000 and 5000. As shown in Table F.9, the results from bootstrapped samples remain similar to the main results. Both in 1000 and 5000 bootstrap samples, the introduction of the Renshi Taiwan textbooks led to a significant decrease in the support for more immigrants.

Second, I re-estimate the model by using a different number of clusters. Instead of clustering at the school cohorts $\times$ educational path, I use clustered standard errors at the school cohorts $\times$ educational attainment level. This increases the number of clusters from about 30 to 160 . Table F.9 (2) shows that changing the level of clusters does not substantially alter the effect of the introduction of the Renshi Taiwan textbooks.

Table F.9: Addressing Different Clustered Robust Standard Errors

\begin{tabular}{lccc}
\hline \hline & \multicolumn{2}{c}{ DV: Preference for increased number of Immigrants } \\
\cline { 2 - 4 } & $(1)$ Bootstrapped CRSEs & \\
\cline { 2 - 4 } & $\begin{array}{c}1000 \text { bootstrap } \\
\text { samples }\end{array}$ & $\begin{array}{c}\text { (2) Education-level CRSEs } \\
\text { samples }\end{array}$ & \\
\hline \hline Academic $\times$ New & $-0.235^{* *}$ & $-0.234^{* *}$ & $-0.228^{* *}$ \\
Academic & $(0.126)$ & $(0.121)$ & $(0.102)$ \\
& $0.560^{* *}$ & 0.567 & $0.553^{*}$ \\
New & $(0.378)$ & $(0.392)$ & $(0.316)$ \\
Constant & 0.116 & 0.115 & 0.122 \\
& $(0.149)$ & $(0.153)$ & $(0.208)$ \\
Observations & $2.450^{* * *}$ & $2.488^{* * *}$ & $2.494^{* * *}$ \\
R-squared & $(0.616)$ & $(0.631)$ & $(0.575)$ \\
\hline \hline
\end{tabular}

Note: All models are estimated using ordinary least squares (OLS). Variables not shown include education level, cohort year, region of birth, and survey year fixed effects along with individual covariates such as gender, employment status, marital status, subjective social class, and high education (college graduate).

$* p<0.1, * * p<0.05, * * * p<0.01$

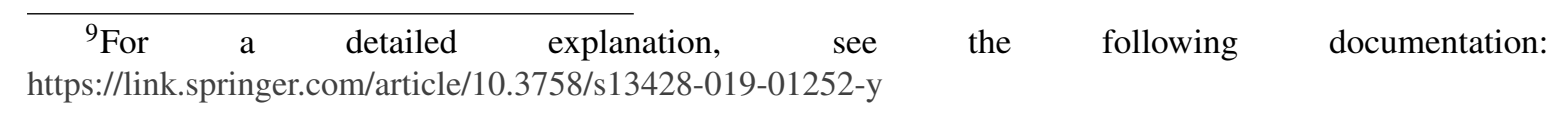

